Article

\title{
Hydrate Production Philosophy and Thermodynamic Calculations
}

\author{
Bjørn Kvamme ${ }^{1, *}$, Jinzhou Zhao ${ }^{1}$, Na Wei ${ }^{1}$, Wantong Sun ${ }^{1}$, Navid Saeidi ${ }^{2}$, Jun Pei ${ }^{1}$ and \\ Tatiana Kuznetsova ${ }^{3}$ \\ 1 State Key Laboratory of Oil and Gas Reservoir Geology and Exploitation, Southwest Petroleum University, \\ Xindu Road No.8, Chengdu 610500, China; zhaojz@swpu.edu.cn (J.Z.); 201131010053@swpu.edu.cn (N.W.); \\ sunwantongswpu@stu.swpu.edu.cn (W.S.); 201921000835@stu.swpu.edu.cn (J.P.) \\ 2 Environmental Engineering Department, University of California, Irvine, CA 92697, USA; saeidin@uci.edu \\ 3 Department of Physics and Technology, University of Bergen, 5007 Bergen, Norway; nfyta@uib.no \\ * Correspondence: bjkvamme@gmail.com
}

Received: 21 December 2019; Accepted: 13 January 2020; Published: 4 February 2020

check for updates

\begin{abstract}
The amount of energy in the form of natural gas hydrates is huge and likely substantially more than twice the amount of worldwide conventional fossil fuel. Various ways to produce these hydrates have been proposed over the latest five decades. Most of these hydrate production methods have been based on evaluation of hydrate stability limits rather than thermodynamic consideration and calculations. Typical examples are pressure reduction and thermal stimulation. In this work we discuss some of these proposed methods and use residual thermodynamics for all phases, including the hydrate phase, to evaluate free energy changes related to the changes in independent thermodynamic variables. Pressures, temperatures and composition of all relevant phases which participate in hydrate phase transitions are independent thermodynamic variables. Chemical potential and free energies are thermodynamic responses that determine whether the desired phase transitions are feasible or not. The associated heat needed is related to the first law of thermodynamics and enthalpies. It is argued that the pressure reduction method may not be feasible since the possible thermal gradients from the surroundings are basically low temperature heat that is unable to break water hydrogen bonds in the hydrate-water interface efficiently. Injecting carbon dioxide, on the other hand, leads to formation of new hydrate which generates excess heat compared to the enthalpy needed to dissociate the in situ $\mathrm{CH}_{4}$ hydrate. But the rapid formation of new $\mathrm{CO}_{2}$ hydrate that can block the pores, and also the low permeability of pure $\mathrm{CO}_{2}$ in aquifers, are motivations for adding $\mathrm{N}_{2}$. Optimum mole fractions of $\mathrm{N}_{2}$ based on thermodynamic considerations are discussed. On average, less than 30 mole $\% \mathrm{~N}_{2}$ can be efficient and feasible. Thermal stimulation using steam or hot water is not economically feasible. Adding massive amounts of methanol or other thermodynamic inhibitors is also technically efficient but far from economically feasible.
\end{abstract}

Keywords: hydrate; non-equilibrium; production

\section{Introduction}

The huge amounts of worldwide energy resources in the form of hydrate are huge. Estimates vary but in view of estimates from USGS from 2000 and the rapid discovery of new hydrate resources it is likely substantially more than twice all known resources of conventional fossil fuels. Most of these hydrates are generated from biogenic hydrocarbon sources, and almost pure methane hydrate. These hydrates are structure I hydrates. Thermogenic sources of hydrocarbons will make a mixture of structure I and II which depends on the hydrocarbon composition. As long as there is availability of propane and iso-butane, structure II formation will dominate. Structure II hydrate contains 16 
small cavities and 8 large cavities with a total of 136 water molecules in a unit cell with side lengths of $17 \AA$. The small cavity is similar to the small cavity in structure I but the large cavity in structure II is larger and contains 28 water molecules in the cavity walls. The combination of a good stabilization by propane and iso-butane of the large cavity, and stabilization of the small cavity by methane, result in low free energy hydrate. Dynamically propane, iso-butane, $\mathrm{CO}_{2}$ and $\mathrm{H}_{2} \mathrm{~S}$ are superior in adsorption on liquid water [1] as compared to supercritical $\mathrm{CH}_{4}$. Even from a thermodynamic point of view it is the properties (chemical potentials and densities) of molecules in the water/gas interface region that determines the hydrate formation pattern and hydrate composition.

There are also other hydrate structures but the cavity size distribution makes them more exotic and rare in nature, although structure $\mathrm{H}$ has been identified in a few places in the Gulf of Mexico [2]. In view of $\mathrm{CH}_{4}$ hydrate dominance in nature, we will limit our discussion to these hydrates in order to simplify the problem and illustrate the thermodynamic analysis.

The paper is organized as follows. The next section gives a fairly basic introduction to multiphase thermodynamics in order to clarify a number of misunderstandings related to hydrates in sediments, and frequent assumptions (and use) of thermodynamic equilibrium. For this reason there are unfortunately few references to other theoretical papers related to $\mathrm{CO}_{2}$ exchange of in situ $\mathrm{CH}_{4}$ hydrate. Mechanisms involved in the conversion are also a limiting factor in some other papers on this system. In the following section we discuss the impact of mineral surfaces on fluid/hydrate thermodynamics and hydrate nucleation aspects. Pressure reduction has been a dominant technology platform for producing hydrates in experiments and pilots. Some important drawbacks and limitations of this approach are discussed in Section 5, followed by a discussion of $\mathrm{CO}_{2}$ injection as a possible win-win approach for energy production and safe storage of $\mathrm{CO}_{2}$. A discussion follows in Section 7 before our conclusions.

\section{Theoretical Background}

Despite the simplicity of only one hydrate former and water, the system is complicated by the fact that hydrates inside sediments are exposed to the issue of there being too many independent variable defined and fixed locally, compared to the number of independent variables that can be defined in order to ensure thermodynamic equilibrium. Temperature is always defined by geothermal gradients and some impact of flow through the sediments, which mix in fluids from neighboring parts (different temperatures) of sediments. Pressure is defined by hydrostatics and hydrodynamics.

The simplest system of these two components is the region of temperatures and pressures in which only two phases exist. This is thermodynamically a very trivial system but still convenient to start with in the derivation of thermodynamic non-equilibrium. If water and $\mathrm{CH}_{4}$ is totally isolated at constant volume then the first law for the composite system of these two phases is:

$$
\begin{gathered}
d \underline{U}^{(a q)}=d Q^{(a q)}-P^{(a q)} d \underline{V}^{(a q)}+\sum_{i=1}^{n} \mu_{i}^{(a q)} d N_{i}^{(a q)} \\
d \underline{U}^{(g a s)}=d Q^{(g a s)}-P^{(g a s)} d \underline{V}^{(g a s)}+\sum_{i=1}^{n} \mu_{i}^{(g a s)} d N_{i}^{(g a s)}
\end{gathered}
$$

The water phase is denoted as $a q$ and the $\mathrm{CH}_{4}$ phase is denoted as gas. $U$ is internal energy and the line beneath denotes extensive energy with the unit Joule. The line under the volume $V$ denotes extensive volume in $\mathrm{m}^{3} . \mathrm{N}$ is number of moles and index I is a counter on components. In this case $i$ is either $\mathrm{CH}_{4}$ or water. The two first terms are trivial in terms of the added heat and the delivered mechanical work, while the last term is frequently denoted as the chemical work. Basically it the work needed release (negative $d N_{i}$ ) molecules from the actual phase. The chemical potential $\mu_{i}^{(a q)}$ is the driving force for this release, and consists of a necessary energy to release the molecules from 
attractions to surrounding molecules, and an entropy contribution related to rearrangements of the remaining molecules.

Since the system is isolated then:

$$
\begin{aligned}
& d \underline{U}^{(a q)}+d \underline{U}^{(g a s)}=0 \\
& d Q^{(a q)}+d Q^{(g a s)}=0 \\
& d \underline{V}^{(g a s)}+d \underline{V}^{(a q)}=0 \\
& d N_{i}^{(g a s)}+d N_{i}^{(a q)}=0
\end{aligned}
$$

The second law of thermodynamics for the system is:

$$
\begin{gathered}
d \underline{S}=d \underline{-}^{(g a s)}+d \underline{-}^{(a q)} \geq 0 \\
\frac{d Q^{(a q)}}{T^{(a q)}}=d \underline{S}^{(a q)} \\
\frac{d Q^{(g a s)}}{T^{(g a s)}}=d \underline{\leftarrow}^{(g a s)}
\end{gathered}
$$

Combining Equations (1), (4), (7) and (8) gives:

$$
d \underline{U}^{(a q)} \leq T^{(g a s)} d \underline{S}^{(a q)}-P^{(a q)} d \underline{V}^{(a q)}+\sum_{i=1}^{n} \mu_{i}^{(a q)} d N_{i}^{(a q)}
$$

Combining Equations (2), (4), (7) and (9) gives:

$$
d \underline{U}^{(g a s)} \leq T^{(a q)} d \underline{S}^{(g a s)}-P^{(g a s)} d \underline{V}^{(g a s)}+\sum_{i=1}^{n} \mu_{i}^{(g a s)} d N_{i}^{(g a s)}
$$

(7), (10) and (11) using (3), (5) and (6) gives:

$$
\begin{aligned}
& d \underline{S}^{r o t a l} \geq d \underline{L}^{(g a s)}\left[\frac{1}{T^{(a q)}}-\frac{1}{T^{(g a s)}}\right]-d V^{(g a s)}\left[\frac{p^{(g a s)}}{T^{(a q)}}-\frac{P^{(a q)}}{T^{(g a s)}}\right] \\
& +\sum\left[\frac{\mu_{j}^{(g a s)}}{T^{(a q)}}-\frac{\mu_{j}^{(a q)}}{T^{(g a s)}}\right] d N_{i}^{(g a s)} \geq 0
\end{aligned}
$$

The only absolute solutions that make stability possible for the system is when the entropy change approaches unconditionally zero when all the terms in the brackets in (12) approach zero.

$$
\begin{gathered}
T^{(a q)}=T^{(g a s)} \\
P^{(a q)}=P^{(g a s)} \\
\mu_{i}^{(a q)}\left(T^{(a q)}, T^{(a q)}, \vec{x}^{(a q)}\right)=\mu_{i}^{(g a s)}\left(T^{(g a s)}, T^{(g a s)}, \vec{y}^{(g a s)}\right)
\end{gathered}
$$

Equation (13) implies that there is no net heat transport between the two phases, Equation (14) is simply Newton's second law while (15) suggests that the average net mass transport between the two phases is zero.

In terms of (15) the number of moles in each phase is not relevant and the conservation of mass reduces to the conservation of mole-fractions in each phase. 
Legendre transforms of (10) and (11) in terms of the entropy results in Helmholtz free energy $A^{\text {total }}$, and the final result for the total system is:

$$
\begin{aligned}
& d \underline{A}^{\text {total }} \leq-\underline{S}^{(a q)} d T^{(g a s)}-P^{(a q)} d \underline{V}^{(a q)}+\sum_{i=1}^{n} \mu_{i}^{(a q)} d N_{i}^{(a q)} \\
& -\underline{S}^{(g a s)} d T^{(a q)}-P^{(g a s)} d V_{-}^{(g a s)}+\sum_{i=1}^{n} \mu_{i}^{(g a s)} d N_{i}^{(g a s)}
\end{aligned}
$$

Equation (16) is the formal thermodynamic basis for Phase Field Theory [2-12] (and references in these) modelling, which will also then include the work of pushing away the original phases to create space for new phase(s).

For flowing systems it is convenient to extract the internal push work. Legendre transforms of the mechanical work terms leads to Gibb's free energy $G_{-}^{\text {total }}$ for the system, in Equation (17) below.

$$
\begin{gathered}
d \underline{G}^{\text {total }} \leq-\underline{S}^{(a q)} d T^{(g a s)}+\underline{V}^{(a q)} d P^{(a q)}+\sum_{i=1}^{n} \mu_{i}^{(a q)} d N_{i}^{(a q)} \\
-\underline{S}^{(g a s)} d T^{(a q)}-\underline{V}^{(g a s)} d P^{(g a s)}+\sum_{i=1}^{n} \mu_{i}^{(g a s)} d N_{i}^{(g a s)}
\end{gathered}
$$

The number of independent variables in Equations (13)-(15) is 8 and the number of conservation equations and conditions of equilibrium, Equations (13)-(15), is 6. Mathematically this system can be solved if two of the independent variables are defined, as also indicated in Table 1 below. A schematic illustration of structure I hydrate is provided in Figure 1. This is a snapshot from a Molecular Dynamics simuation set-up in which the guest molecules are scaled down. In Table 1 we limit ourselves to counting only two hydrates. One hydrate is formed between gas hydrate former from a separate. A second hydrate phase if formed from hydrate former dissolved in liquid water.

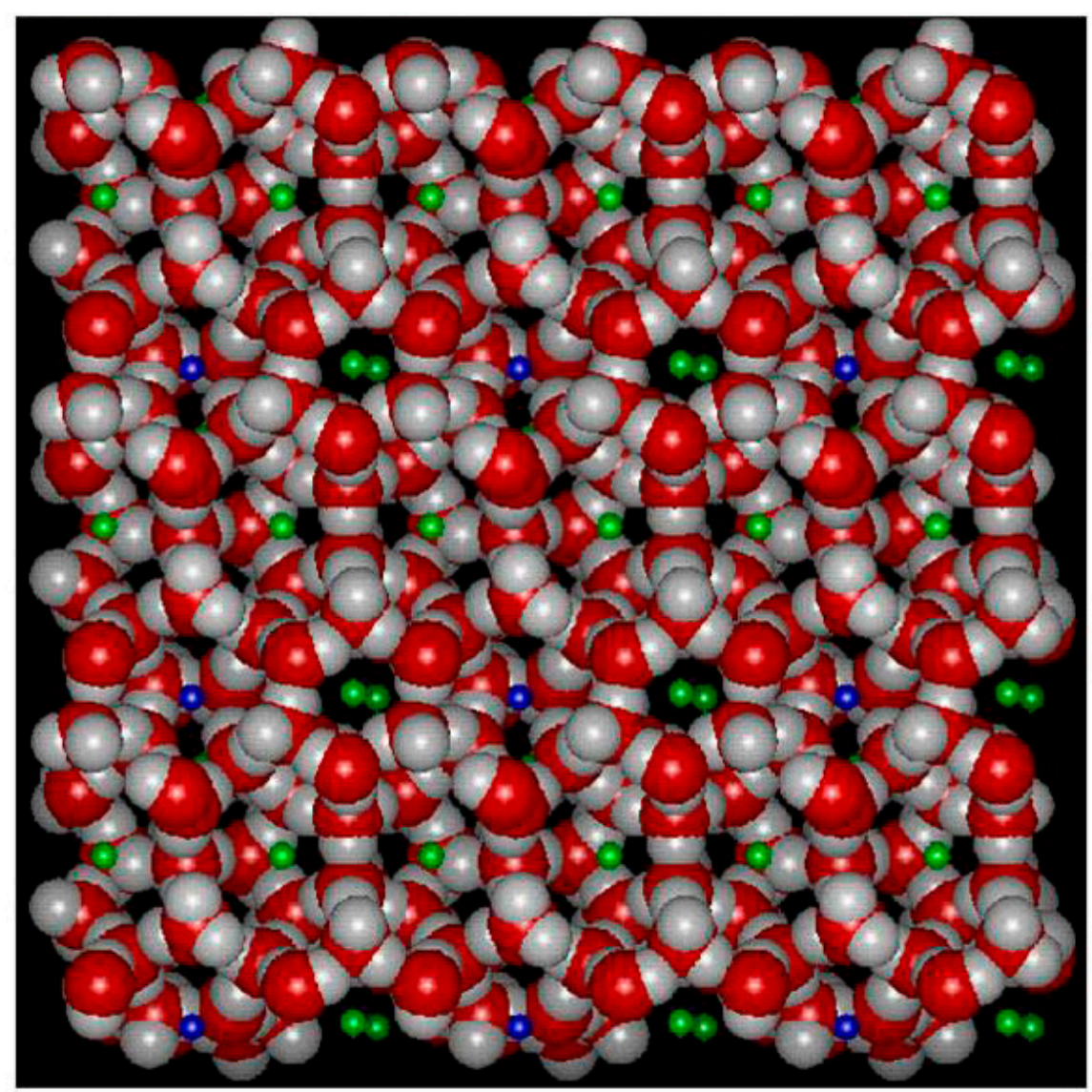


Figure 1. A molecular dynamics simulation snapshot of a structure I unit call in 2D projection. Red is oxygen, grey is hydrogen and green and blue visualizing downscaled guests in large and small cavities. Only one molecule per cavity and the double green just visualize two different cavity fillings in the third dimension. The average unit cell is a cube with side wall lengths of 12.01 Angstrøms. This smallest symmetrical unit cell contains 46 water molecules and forms 2 small cavities made up from 20 hydrogen bonded water molecules, and 6 large cavities made up from 24 hydrogen bonded water molecules. Structure I fits molecules like for instance $\mathrm{CH}_{4}, \mathrm{C}_{2} \mathrm{H}_{4}, \mathrm{C}_{2} \mathrm{H}_{6}, \mathrm{H}_{2} \mathrm{~S}$ and $\mathrm{CO}_{2}$.

Table 1. Numbers of independent thermodynamic variables versus conservation laws and equilibrium equations.

\begin{tabular}{|c|c|c|c|c|}
\hline Var. no. & Variable & Eq, no & Equation & Diff. \\
\hline 1 & $x_{\mathrm{CH}_{4}}^{g a s}$ & 1 & $x_{\mathrm{CH}_{4}}^{g a s}+x_{\mathrm{H}_{2} \mathrm{O}}^{g a s}=1$ & \\
\hline 2 & $x_{\mathrm{CH}_{4}}^{a q .}$ & 2 & $x_{\mathrm{CH}_{4}}^{a q .}+x_{\mathrm{H}_{2} \mathrm{O}}^{a q .}=1$ & \\
\hline 3 & $x_{\mathrm{H}_{2} \mathrm{O}}^{\text {gass }}$ & 3 & $T^{g a s}=T^{a q}$ & \\
\hline 4 & $x_{\mathrm{H}_{2} \mathrm{O}}^{a q .}$ & 4 & $P^{g a s}=P^{a q}$ & \\
\hline 5 & $T^{g a s}$ & 5 & $\mu_{\mathrm{CH}_{4}}^{g a s}=\mu_{\mathrm{CH}_{4}}^{a q}$ & \\
\hline 6 & $T^{a q}$ & 6 & $\mu_{\mathrm{H}_{2} \mathrm{O}}^{g a s}=\mu_{\mathrm{H}_{2} \mathrm{O}}^{a q}$ & \\
\hline 7 & $P^{g a s}$ & & & \\
\hline 8 & $p^{a q}$ & & & \\
\hline 2 phase & 8 & 6 & & 2 \\
\hline 9 & $x_{\mathrm{CH}_{4}}^{\mathrm{H}}$ & 7 & $x_{\mathrm{CH}_{4}}^{\mathrm{H}}+x_{\mathrm{H}_{2} \mathrm{O}}^{\mathrm{H}}=1$ & \\
\hline 10 & $x_{\mathrm{H}_{2} \mathrm{O}}^{\mathrm{H}}$ & 8 & $T^{H}=T^{a q}$ & \\
\hline 11 & $T^{H}$ & 9 & $P^{H}=P^{a q}$ & \\
\hline \multirow[t]{2}{*}{12} & $P^{H}$ & 10 & $\mu_{\mathrm{CH}_{4}}^{\mathrm{H}}=\mu_{\mathrm{CH}_{4}}^{a q}$ & \\
\hline & & 11 & $\mu_{\mathrm{H}_{2} \mathrm{O}}^{\mathrm{H}}=\mu_{\mathrm{H}_{2} \mathrm{O}}^{a q}$ & \\
\hline 3 phase & 12 & 11 & & 1 \\
\hline 13 & $x_{\mathrm{CH}_{4}}^{\mathrm{H}_{a q}}$ & 12 & $x_{\mathrm{CH}_{4}}^{\mathrm{H}_{a q}}+x_{\mathrm{H}_{2} \mathrm{O}}^{\mathrm{H}_{a q}}=1$ & \\
\hline 14 & $x_{\mathrm{H}_{2} \mathrm{O}}^{\mathrm{H}_{a q}}$ & 13 & $T^{H_{a q}}=T^{a q}$ & \\
\hline 15 & $T^{H_{a q}}$ & 14 & $P^{H_{a q}}=P^{a q}$ & \\
\hline \multirow[t]{2}{*}{16} & $P^{H_{a q}}$ & 15 & $\mu_{C_{a}}^{H_{a q}}=\mu_{C H_{4}}^{a q}$ & \\
\hline & & 16 & $\mu_{\mathrm{H}_{2} \mathrm{O}}^{H_{a q}}=\mu_{\mathrm{H}_{2} \mathrm{O}}^{a q}$ & \\
\hline 4 phase & 16 & 16 & & 0 \\
\hline 17 & $x_{\mathrm{CH}_{4}}^{\text {ads. }}$ & 17 & $x_{\mathrm{CH}_{4}}^{a d s .}+x_{\mathrm{H}_{2} \mathrm{O}}^{a d s .}=1$ & \\
\hline 18 & $x_{\mathrm{H}_{2} \mathrm{O}}^{a d s .}$ & 18 & $T^{a d s .}=T^{a q .}$ & \\
\hline 19 & $T^{a d s .}$ & 19 & $P^{a . d s}=P^{a q .}$ & \\
\hline \multirow[t]{2}{*}{20} & $p^{a d s .}$ & 20 & $\mu_{\mathrm{CH}_{4}}^{a d s .}=\mu_{\mathrm{CH}_{4}}^{a q}$ & \\
\hline & & 21 & $\mu_{\mathrm{H}_{2} \mathrm{O}}^{a d s}=\mu_{\mathrm{H}_{2} \mathrm{O}}^{a q}$ & \\
\hline
\end{tabular}


Table 1. Cont.

\begin{tabular}{|c|c|c|c|c|}
\hline Var. no. & Variable & Eq, no & Equation & Diff. \\
\hline 5 phase & 20 & 21 & & -1 \\
\hline 21 & $x_{\mathrm{CH}_{4}}^{\mathrm{H}, \mathrm{ads} .}$ & 22 & $x_{\mathrm{CH}_{4}}^{\mathrm{H}, \mathrm{ads}}+x_{\mathrm{H}_{2} \mathrm{O}}^{\mathrm{H}, \mathrm{adds}}=1$ & \\
\hline 22 & $x_{\mathrm{H}_{2} \mathrm{O}}^{\mathrm{H}, \mathrm{ads}}$ & 23 & $T^{H, a d s .}=T^{a q .}$ & \\
\hline 23 & $T^{H, a d s .}$ & 24 & $P^{H, a d s}=P^{a q .}$ & \\
\hline \multirow[t]{2}{*}{24} & $P^{H, a d s .}$ & 25 & $\mu_{\mathrm{CH}_{4}}^{\mathrm{H}, \text { ads. }}=\mu_{\mathrm{CH}_{4}}^{a q .}$ & \\
\hline & & 26 & $\mu_{\mathrm{H}_{2} \mathrm{O}}^{\mathrm{H}, \text { ads. }}=\mu_{\mathrm{H}_{2} \mathrm{O}}^{a q .}$ & \\
\hline 6 phase & 24 & 26 & & -2 \\
\hline
\end{tabular}

Detailed models for water and methane chemical potentials in the two phases can be found in Kvamme [13,14] and Kvamme et.al. [15] and will not be repeated here. Numerical solutions for the distribution of the two components in gas and water for various combinations of temperature and pressure are given in Figure 2.

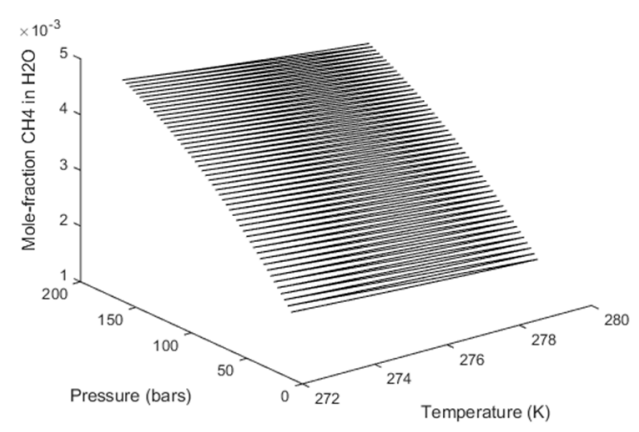

(a)

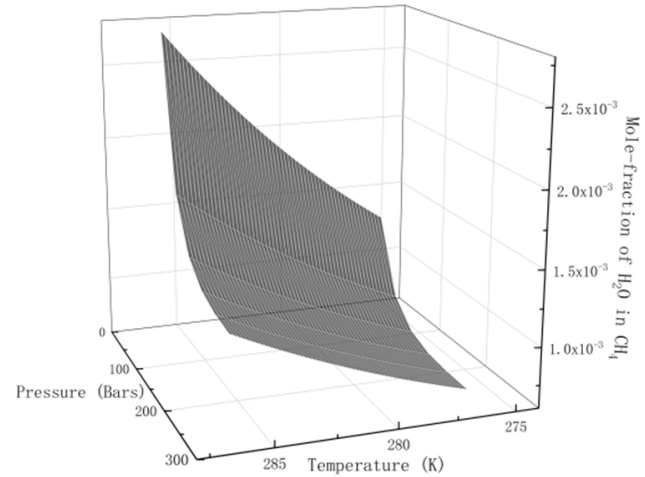

(b)

Figure 2. (a) Solubility of $\mathrm{CH}_{4}$ in $\mathrm{H}_{2} \mathrm{O}$. (b) Solubility of $\mathrm{H}_{2} \mathrm{O}$ in $\mathrm{CH}_{4}$.

Moving the system into the hydrate-forming region of temperature and pressure now reduces the system to 1 degree of freedom. In practical terms, this means that only one independent variable can be defined if the system should be able to reach thermodynamic equilibrium. This is well known in measurements of hydrate equilibrium. Classically it has often been measured by the hydrate dissociation temperature for a fixed pressure. But there is a theoretical ambiguity to this, which is visible when looking at models for hydrate from statistical mechanics.

Van der Waals and Platteeuw [16] used a semi Grand Canonical ensemble to derive a Langmuir-type adsorption theory in which water molecules are fixed and rigid while molecules that enter cavities (guest molecules) are open to exchange with surrounding phases. The final result of the derivation is expressed in terms of chemical potential for water in hydrate:

$$
\mu_{\mathrm{H}_{2} \mathrm{O}}^{\mathrm{H}}=\mu_{\mathrm{H}_{2} \mathrm{O}}^{\mathrm{O} H}-\sum_{k=1,2} R T v_{k} \ln \left(1+\sum_{i} h_{i j}\right)
$$

$\mu_{\mathrm{H}_{2} \mathrm{O}}^{\mathrm{O} \mathrm{H}}$ is the chemical potential for water in an empty clathrate for the given structure in consideration. $k$ is an idex for cavity types and $j$ is an index for guest molecules in the various cavities. The number of cavities is $v$, with bubscripts $k$ for large and small cavities respectively. For structure $\mathrm{I}$, which is the 
main focus here, $v_{\text {large }}=3 / 24$ and $v_{\text {small }}=1 / 24$. For structure II the corresponding numbers are $v_{\text {large }}=$ $1 / 17$ and $v_{\text {small }}=2 / 17$.

Historically, thus, value has not been calculated by theoretical methods but rather fitted to experimental data in the form of chemical potential of pure liquid water minus empty clathrate water chemical potential. Kvamme and Tanaka [17] used molecular dynamics simulations to calculate empty clathrate water chemical potentials, as well as chemical potentials for ice and liquid water. In contrast to the original van der Waals and Platteuw [16] derivation, the canonocal partition function for the cavities (see below) is not contrained to a rigid water lattice in the formulation of Kvamme the Tanaka [17]. Harmonic oscillator models for large guest molecules relative to cavity is more accurate than rigid water lattice model, and samplings directly points at frequencies of guest movement that affects water librations. Smaller guest molecules are better represented by the classical integration over Boltzmann factors for interactions between water and guest in the cavity volume.

Most hydrate codes use the original van der Waals and Platteeuw [16] with a fixed lattice and fugacity instead of chemical potentials to desctibe hydrate former phase. See Sloan and Koh [18] for the historical treatment of hydrate phase transitions and equilibrium. See also Kvamme and Førrisdahl [19] for polar guest molecules and Kvamme and Lund [20] for effects of guest-guest interactions.

$$
h_{k i}=e^{\beta\left[\mu_{k i}^{H}\left(T, P, \vec{x}^{H}\right)-\Delta g_{k i}(T)\right]}
$$

where $\beta$ is the inverse of the universal gas constant times temperature. At equilibrium, the chemical potential of the guest molecules $i$ in hydrate cavity $k$ is equal to the chemical potential of molecules $i$ in the co-existing phase it comes from. For non-equilibrium, the chemical potential is adjusted for distance from equilibrium through a Taylor expansion.

$$
\begin{aligned}
& \mu_{k i}^{H}\left(T, P, \vec{x}^{H}\right)=\mu_{k i}^{H}\left(T^{E q \cdot,} P^{E q .}, \vec{x}^{H, E q .}\right) \\
& +\left.\sum_{r} \frac{\partial \mu_{k i}^{H}\left(T, P, \vec{x}^{H}\right)}{\partial x_{r}}\right|_{P, T, x_{i \neq r}}\left(x_{r}-x_{r}^{H, E q .}\right) \\
& +\left.\frac{\partial \mu_{k i}^{H}\left(T, P, \vec{x}^{H}\right)}{\partial P}\right|_{T, \vec{x}}\left(P-P^{H, E q .}\right)+\left.\frac{\partial \mu_{k i}^{H}\left(T, P, \vec{x}^{H}\right)}{\partial T}\right|_{P, \vec{x}}\left(T-T^{E q \cdot}\right)
\end{aligned}
$$

Examples of free energies of inclusion (latter term in the exponent) are reported elsewhere [21-25]. At thermodynamic equilibrium between a free hydrate former phase, $\mu_{k i}$ is the chemical potential of the guest molecule in the hydrate former phase (gas, liquid, or fluid) at the hydrate equilibrium temperature and pressure.

The composition of the hydrate is also trivially given by the derivation from the semi-grand canonical ensemble and given by:

$$
\theta_{k i}=\frac{h_{k i}}{1+\sum_{j} h_{k i}}
$$

$\theta_{k i}$ is the filling fraction of component $i$ in cavity type $k$. Also:

$$
\begin{aligned}
& x_{i, \text { large }}^{H}=\frac{\theta_{\text {large }, i} v_{\text {large }}}{1+\theta_{\text {large }, i} v_{\text {large }}+\theta_{\text {small }, i} v_{\text {small }}} \\
& x_{i, \text { small }}^{H}=\frac{\theta_{\text {small }, i} v_{\text {small }}}{1+\theta_{\text {large }, i} v_{\text {large }}+\theta_{\text {small }, ~} v_{\text {small }}}
\end{aligned}
$$


where $v$ is the fraction of cavity per water for the actual cavity type, as indicated by subscripts. The corresponding mole-fraction water is then given by:

$$
x_{\mathrm{H}_{2} \mathrm{O}}^{\mathrm{H}}=1-\sum_{i} x_{i, \text { large }}^{\mathrm{H}}-\sum_{i} x_{i, \text { small }}^{H}
$$

and the associated hydrate free energy is then:

$$
G^{(H)}=x_{H_{2} \mathrm{O}}^{H} \mu_{H_{2} \mathrm{O}}^{H}+\sum_{i} x_{i}^{H} \mu_{i}^{H}
$$

The composition of the initial hydrate, and the free energy of the hydrate created initially, depends on the conditions of temperature and pressure at which the hydrate was formed. But a review of experimental data and experimental methods is outside the scope of this work.

Temperature and pressure are always both defined in real cases. For hydrates in nature the temperature is controlled by geothermal gradients and flow, and pressure is defined by hydrostatics and flow. Hydrate formation in pipelines and industrial equipment is always happening at locally defined temperatures and pressures. Heat transport is typically 2-3 orders of magnitude faster than mass transport [7] (and enclosed papers) in water systems, but slow through $\mathrm{CH}_{4}$. Mechanical stability between liquid water and hydrate is fast but mechanical stability between gas phase and other phases is slower.

What is important, however, is that there is no simple rule on equal chemical potentials for all components in all phases. Local chemical potentials of all components in all phases, and corresponding distribution of masses over the various phases are determined by an extension of (17) to include all co-existing phases, under constraints of mass and heat transport. An important implication of this is that the chemical potential of $\mathrm{CH}_{4}$ in the gas phase can generally be different from the chemical potential for $\mathrm{CH}_{4}$ in the water phase. With reference to (19) and (21) to (25) we can expect at least two different hydrates, one type of hydrate formed from gas $\mathrm{CH}_{4}$ and water and another hydrate from $\mathrm{CH}_{4}$ dissolved in water. The degrees of freedom will, therefore, reduce to zero and the system is mathematically over-determined by two independent thermodynamic variables.

In Figure 3 we plot the limits of hydrate stability in pressure, temperature and concentration of $\mathrm{CH}_{4}$ in surrounding water, and in Figure $3 \mathrm{~b}$ we plot the stability limits of hydrate as a function of concentration for variations of temperature and pressure. I.e.: Even if hydrate forms according to the temperature and pressure stability limits in Figure 3 a there will still be competing processes of hydrate dissociation if the surrounding water contains less $\mathrm{CH}_{4}$ than the black contour for concentrations as functions of temperature and pressure. Hydrate can form from concentrations in between the concentration contour in Figure 2a and the lowest limit of hydrate stability in Figure 3a. Hydrate formation from gas is theoretically possible for water concentrations equal to, or higher, than the values in the contour of Figure 3b. Any water concentrations lower than concentrations in Figure $3 b$ will lead to hydrate sublimation. While hydrate is, theoretically, possible from dissolved water in gas, from a thermodynamic point of view, it is obvious that the logistics of merging water molecules enough to create hydrate is a challenge. Getting rid of formation heat adds to the challenge. $\mathrm{CH}_{4}$ gas is an efficient heat insulator. 


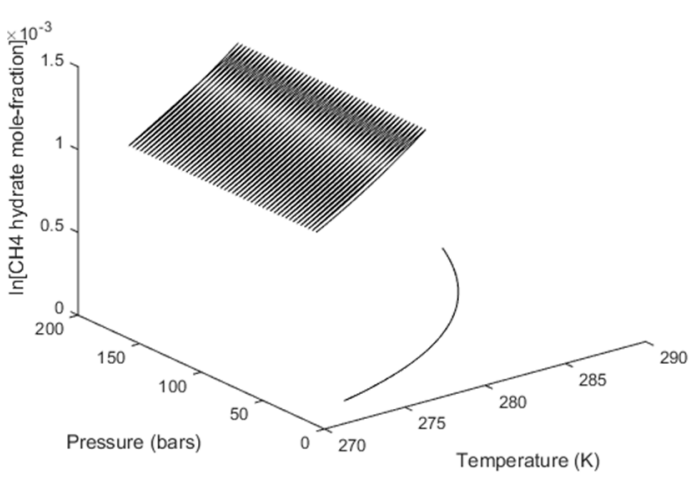

(a)

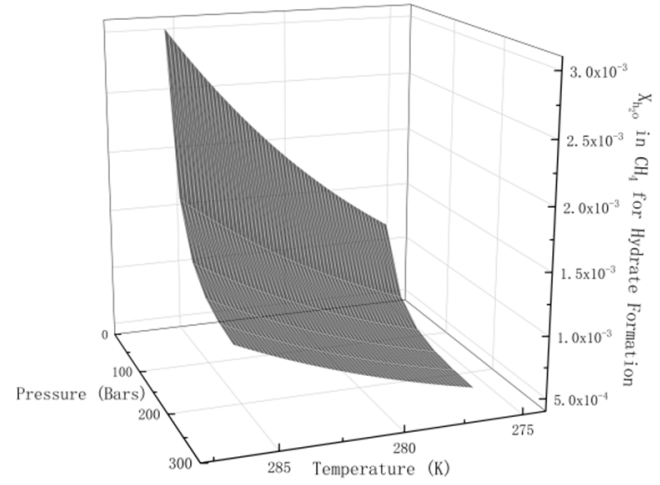

(b)

Figure 3. (a) Limits of $\mathrm{CH}_{4}$ hydrate formation in the pressure temperature projection. No hydrate for any pressure below the curve. (b) Limits of $\mathrm{CH}_{4}$ hydrate stability as function of mole-fraction $\mathrm{CH}_{4}$ in surrounding water.

As will be discussed in more detail later, the three different situations in Figure 3 give different hydrates. Hydrate formation from gas will not be discussed further since it is not important and even unlikely to happen due to limitations in mass and heat transport. But hydrates from solution can be far more than just one since the contours in Figure $3 a$ is the lowest limit of hydrate stability and the hydrates of lowest stability. The closer the water concentration approaches the concentrations in Figure 2a, the more stable the hydrate that is formed. From a mathematical perspective the concentration ranges between the concentration contours in Figures 2a and $3 a$ an infinite number of different hydrates can be formed from solution of $\mathrm{CH}_{4}$ in water. In practical terms, there will of course be competition on mass which over time will lead to reorganization in the direction that more stable hydrates will consume less stable hydrate.

In the more general situation the combination of first and second laws of thermodynamics can be expressed by Equation (26) for a number of different phases. $m$ is a phase index and $m$, surr. denotes temperature effects from all surroundings and will not be a single source and one temperature in a general non-equilibrium situation. In contrast to energy and mass entropy-related quantities are non-conserved and (26) simply says that the system will locally develop towards minimum free energy as a function of the independent thermodynamic variables in the system. If we assume that the multi-phase version of Equations (13) and (14) are fulfilled then the minimum of Equation (26), under constraints of mass and energy conservation, gives the thermodynamically most likely distribution of phases, and associated composition of these phases.

$$
d \underline{G}^{\text {total }} \leq \sum_{m=1}^{\text {phases }}-S_{-}^{(m)} d T^{(m, \text { surr. })}+\underline{V}^{(m)} d P^{(m)}+\sum_{i=1}^{n . m} \mu_{i}^{(m)} d N_{i}^{(m)} \leq 0
$$

The minimum of Equation (26) does not mean that each local phase at a given time is unconditionally stable. Quite the opposite is true. For a phase to be unconditionally stable the additional constraints must be fulfilled:

$$
\left[\frac{\partial \underline{G}^{(m)}}{\partial M}\right]_{K \neq M} \delta M \leq 0
$$

for any possible range of changes of independent variable $\mathrm{M}$.

The symbol $K$ is used as a general index for thermodynamic variables in all co-existing phases. $M$ is also an index for all independent thermodynamic variables in all co-existing phases. For a 
flowing system the energy level is most conveniently expressed in terms of enthalpy and the enthalpy corresponding to the same multi-components system is given by:

$$
d \underline{H}^{\text {total }} \leq \sum_{m=1}^{\text {phases }} d Q^{(m)}+\underline{V}^{(m)} d P^{(m)}+\sum_{i=1}^{n . m} \mu_{i}^{(m)} d N_{i}^{(m)}
$$

Superscript $m$ indicates added heat to phase $m$ from any surrounding, including all other phases and external sources.

Equations (26)-(28) express, in short, the motivation of this paper. Very often hydrate production potential is evaluated based on projections of independent thermodynamic variables with careful calculations of whether the thermodynamic changes are large enough to provide feasible production from hydrate. There is always a complete thermodynamic picture in which (26) and (27) enters phase transition dynamics while the associated energy changes must be supported by the first law of thermodynamics Equation (28).

Some few trivial examples are mentioned here. Some of these will be discussed in more detail in separate sections of the paper. The pressure temperature projection of Figure 3a will result in hydrate formation if $\mathrm{CH}_{4}$ and liquid water are contacted inside the stability limits in the $T, P$ projection. But this hydrate will dissociate according to Equation (27) if the surrounding water is "permitted" to have values below the black concentration contour in Figure 3a. As will be discussed in more in a section on porous media and impact of mineral surfaces water can be kicked out from gas phase by very favourable adsorption on mineral surfaces. The density of adsorbed water on mineral surfaces can be three times liquid density and associated water chemical potential are far lower than liquid water chemical potential and hydrate water chemical potential. As such it is absolutely possible that mineral surfaces dry out $\mathrm{CH}_{4}$ gas, and subsequently lead to hydrate dissociation towards gas according to Figure $3 \mathrm{~b}$. Similar things can happen in pipelines transporting gas containing water or in multiphase flow pipeline transporting hydrocarbons and water. With extremely few exceptions all pipelines in the oil and gas industry are rusty even before they are mounted. Rust generated by water and oxygen is a mixture of magnetite $\left(\mathrm{Fe}_{3} \mathrm{O}_{4}\right)$, hematite $\left(\mathrm{Fe}_{2} \mathrm{O}_{3}\right)$ and iron oxide $(\mathrm{FeO})$.

The paper is organised as follows. Impact of mineral surfaces on hydrate stability and hydrate nucleation is briefly discussed in the next section. This is followed by a section discussing the role of free energies and enthalpies in hydrate production. The paper is completed with a discussion section and our conclusions.

\section{Hydrates in Porous Media}

Hydrates in porous media are affected by the solid material in at least four different ways. Small pore channels (roughly less than $10-50 \mathrm{~nm}$ depending on solid walls) put constraints on hydrate expansion and result in extra strain in the hydrate lattice. In practice this means that higher stabilization (lower temperature and/or higher pressure) is needed for hydrate to form. There are many papers on this aspect but it is not an important issue for the most valuable targets for hydrate production, which are hydrates in unconsolidated sediments. The larger the grain sizes the larger the pore volumes. Geometrical inclinements between solid particles results in constraints on local movements of molecules and gives more time for rearrangements and nucleation; see for instance Svandal [7] and Buanes [10] and papers included in these PhD theses for Phase Field Theory modelling of phase transition dynamics in confined geometries.

In this work we utilize a simpler theory. The motivation for this is to develop a concept that is theoretically rigorous enough to capture the most important dynamic phenomena related to hydrate formation and dissociation while still being simple enough to include in flow modelling in porous media. Multi-components Diffuse Interface Theory (MDIT) $[26,27]$ is as numerically simple as Classical Nucleation Theory (CNT). Two limitations of the original CNT are the absence of interface between new and old phases, and the mass transport flux related to the phase transition. The original pre factor 
to the thermodynamic control of the phase transition was only developed for one component and ideal transport. These two aspects have both been modified by Kvamme [13,14], and Kvamme et.al. [15,28]. The result is new models for the mass transport terms in the Classical Nucleation Theory. The final theory is still numerically simple and useful.

The empirical models due to Kim and Bishnoi [29] utilized in most current hydrate reservoir simulators do not have any physical relevance. That correlation was developed as an empirical model for fitting experimental data for hydrate dissociation under various stirring rates in Pressure Volume Temperature (PVT) experiments, without presence of porous media.

The modified version of CNT and the use of residual thermodynamics for all phases, including hydrate phase [17] provides a consistent concept that also includes enthalpies of hydrate formation and dissociation from the same concept $[14,15,30]$.

Minerals structure water and lead to extreme densities of the first layers of adsorbed water compared to liquid water densities. We have conducted Molecular Dynamics simulations of water and hydrate formers in contact with various mineral surfaces using LAMMPS [31]. Our recent molecular dynamics studies of water adsorbed on calcite [32] indicate that the density of the first water layer may be as high as 3 times the density of liquid water. Experimental data [33] have a slightly lower first peak for water density but broader peaks. For all practical purposes, like for instance number of nearest neighbours, the agreement between modelling and experimental data is very good. Some polar molecules, like for instance $\mathrm{H}_{2} \mathrm{~S}$, adsorb directly on Calcite in competition with water [34,35]. The significant quadrupole moment of $\mathrm{CO}_{2}$ also leads to direct adsorption on Calcite [36]. Hydrate can therefore form from water outside the Calcite surface where water is close to liquid water in structure, and adsorbed hydrate formers.

However, non-polar hydrate formers, like for instance $\mathrm{CH}_{4}$, can also be trapped in structured water [36-38] and lead to hydrate nucleation when the water is in contact with a separate hydrate former phase [36]. In the absence of a separate hydrate former phase hydrate nucleation like structures are still observed but they dissolve due to low concentration of hydrate formers in water.

Mineral surfaces will therefore act as hydrate inhibitors since hydrate water can never touch mineral surfaces due to the low chemical potential of water in the first adsorbed layers. But mineral surfaces up concentrate hydrate formers through direct adsorption or secondary adsorption in water structures and serve as hydrate nucleation sites. Formed hydrate nuclei can be bridged to the surface of minerals by more or less structured water. A simple model system [36] illustrating the trapping of $\mathrm{CH}_{4}$ in structured water will be discussed below.

The model system built in [36] comprised several slabs of varying thickness and compositions, with the main ones being calcite and water. A thin phase of methane was introduced between the water phase and the calcite slab on one side, while a thick methane phase was positioned to the other to mitigate the effect of fluctuations on adsorbed methane molecules on the surface due to the volume change of the primary cell. The dimensions of the resulting primary cell for simulation were $39.9 \AA \times$ $48.6 \AA \times 170 \AA$, and it contained 16,207 atoms.

The crystal structure and all liquid phases were created separately and then combined to build the composite system. MD package LAMMPS [31] was used to implement MD simulations with the time step set to $0.1 \mathrm{fs}$ for the first $1 \mathrm{ps}$ to equilibrate the system. The time step was then increased to $1 \mathrm{fs}$ to achieve equilibrium. During the equilibration run, methane was completely replaced by water on surfaces and thus did not affect the result analysis in this respect. The total equilibration time amounted to $0.501 \mathrm{~ns}$. The production run with the time step increased to $1 \mathrm{fs}$ was conducted for $1.5 \mathrm{~ns}$. An NPT ensemble was emulated, with temperature and pressure (in the z-direction) set to $273 \mathrm{~K}$ and 100 bar, respectively, via the application of a Nose-Hoover thermostat and barostat. Periodic boundary conditions were applied in all three directions. The L-J potential was used to model the short-range molecular interactions with a cut-off distance of $10 \mathrm{~A}^{\circ}$, whereas PPPM was used to evaluate electrostatic interactions. The calcite slab atoms were kept fixed at their crystallographic positions. The forcefield parameters used to calculate the potential energy of the systems can be found in Tables 
8.2-8.5 of [36]. The SHAKE algorithm was used to restore the original bond length and angle of water molecules at each time step. Bond and angle potential contributions were included in this simulation based on harmonic style.

Initially methane adsorbed directly onto the calcite surface despite the absence of partial charges in the one-site L-J model for methane. As simulation progressed, methane and water competed to adsorb on the calcite surface. Water completely replaced methane from the surface since calcite preferred to adsorb water. The water adsorption pattern of the first two layers appeared significantly influenced by the presence of methane, and the time needed to replace the methane completely was about $0.4 \mathrm{~ns}$. The primary layer of water on the calcite-water interface displayed a peak located around $2.28 \AA$ from the surface calcium atom, a distance comparable to the previous experimental and theoretical findings. The next water layer which was still more structured than the water bulk was found at $3.48 \AA$ from the surface. The vigorous interactions between water and the calcite surface can be attributed the strong hydrogen bonding between the two phases. The distance between the first and the second adsorbed layers of water was very small, leaving no space for methane to aggregate. The presence of methane was observed after the second adsorbed layer, with its presence becoming more obvious outside of $6 \AA$ from the calcite surface, as shown in Figures 4 and 5. It was there that the formed methane bubble became trapped, with its location oscillating between 7 and $13 \AA$ from the surface. The methane was not able to escape through the water phase to join the main methane phase within the time span covered in the simulation, with the trapped molecules mainly consisting of those inserted between the calcite surface and the water phase to probe their behaviour under such circumstances. Very few dispersed methane molecules were found in the water phase, as expected from its extremely low solubility. Figure 6 traces the time evolution of methane behaviour during the simulation.

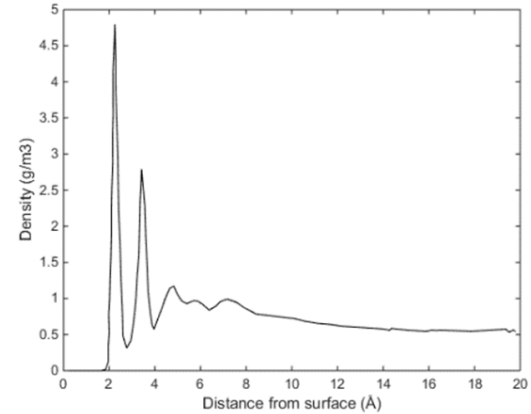

(a)

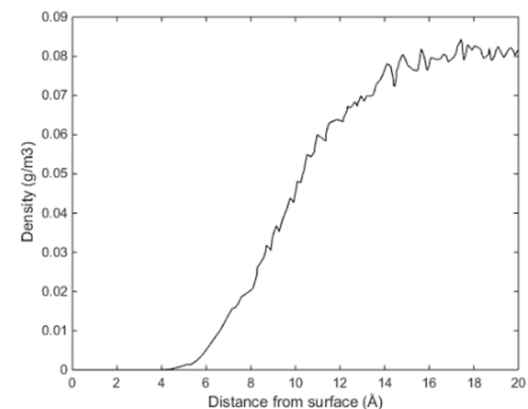

(b)

Figure 4. (a) Sampled density of water as function of distance from calcite surface and (b) sampled density of $\mathrm{CH}_{4}$ as function of distance from calcite surface.

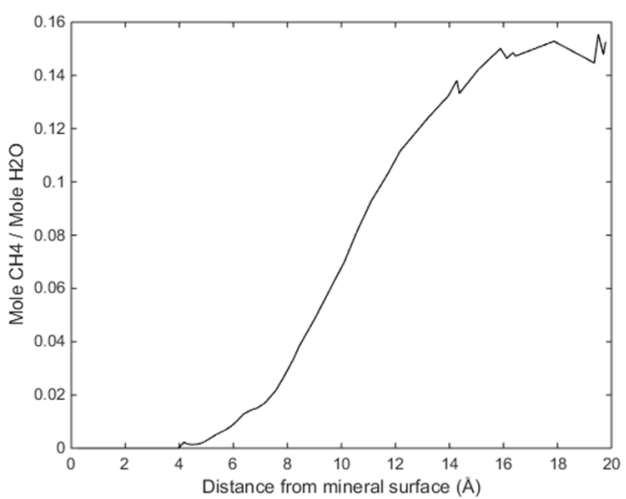

(a)

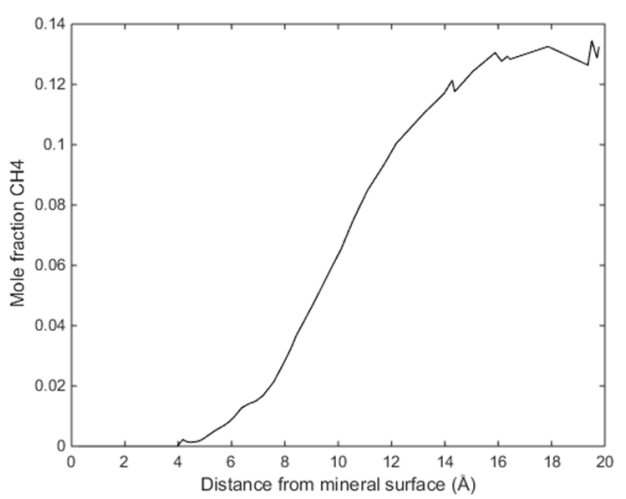

(b)

Figure 5. (a) Ratio of $\mathrm{CH}_{4}$ molecules to water molecules as function of distance from calcite surface and (b) mole fraction $\mathrm{CH}_{4}$ as function of distance from calcite. 

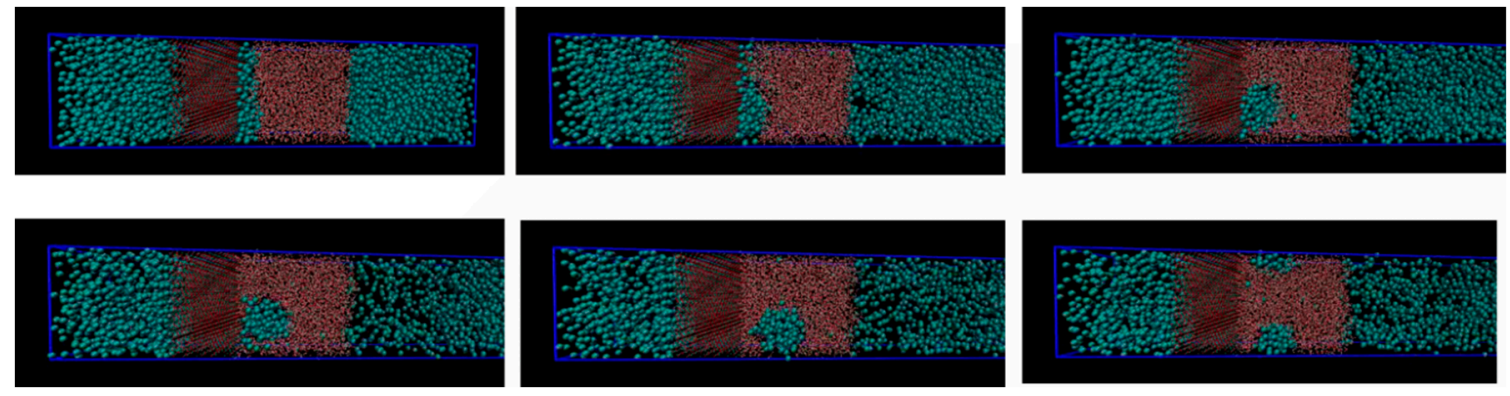

Figure 6. Time evolution of methane layer initially positioned in direct contact with the calcite slab.

The size of the system under study was rather limited, and we are not claiming that the samples in Figures 3 and 4 are representative enough to serve a rigorous nucleation sampling. Larger systems with similar set-up will be investigated in a separate study. The primary information we want to share with these figures is that there are certainly $\mathrm{CH}_{4}$ trapping effects related to water structures generated by calcite surfaces, and composition of the small nuclei is even close to stable hydrate composition in the centre of the $\mathrm{CH}_{4}$ accumulations.

\section{Pressure Reduction Scenario}

Of all the hydrate production methods that have been proposed and examined during the last four decades, pressure reduction has been that examined most in laboratory experiments and pilot plant studies. What is missing in open literature is a more detailed thermodynamic analysis which can shed more light on what is to be expected from this method. Visualization in a pressure temperature diagram does not tell us anything directly about thermodynamic changes. It gives an idea that hydrate can be brought outside stability limits but what are the actual thermodynamic driving forces for dissociating the hydrate, i.e., the free energy change. The second question is: how can the heat of dissociation be supplied in sufficient amounts for commercially feasible production from natural gas hydrates?

The temperature pressure projection of the stability limits for $\mathrm{CH} 4$ hydrate is plotted in Figure 7 below. Temperature, pressure and compositions of all co-existing phases are independent variables while free energy and chemical potentials are the thermodynamic responses of relevance for phase stability and driving forces for phase transitions. The free energy of hydrate formed along the pressure temperature stability limit curve is plotted in Figure $7 \mathrm{~b}$. In Figure $7 \mathrm{a}$ we also plot in a pressure reduction example scenario. An initial condition of a $\mathrm{CH}_{4}$ hydrate of $278 \mathrm{~K}$ and 120 is reduced to a pressure of 10 bar and $274 \mathrm{~K}$. This is, of course, a very arbitrary example but useful for illustrating two aspects. Pressure reduction on a solid hydrate inside pressure temperature stability zone will not be entirely isothermal since there will be restructuring to lower filling fractions when pressure reduction brings the hydrate down to stability limit pressure. The enthalpy changes related to these processes are expected to be very limited but can be calculated. In Figure 5 this part of the pressure reduction is dashed in Figure 5. Dissociation of the hydrate, and expansion of the released gas, is a kinetic problem that will be discussed separately. At this moment it is simply a dash dot line between the hydrate stability limit pressure and the final condition in Figure 7. 


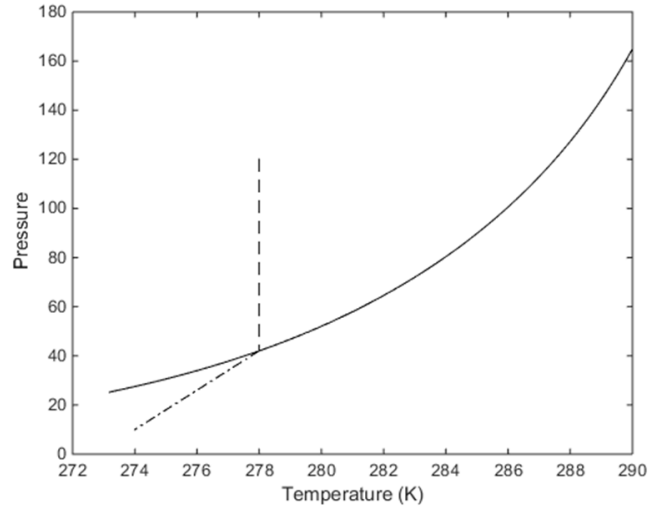

(a)

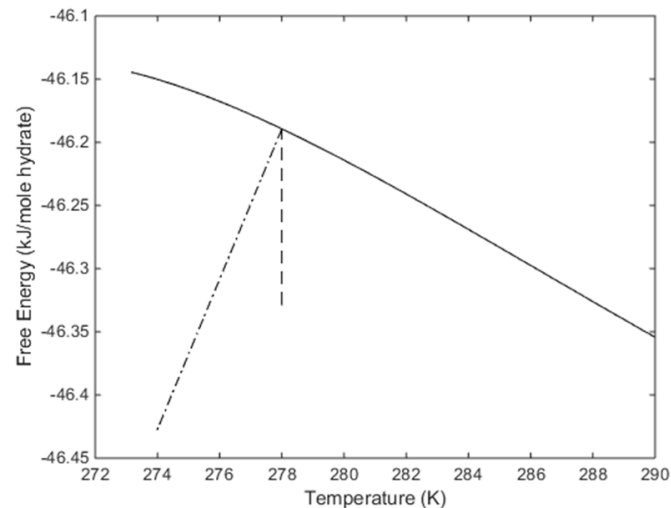

(b)

Figure 7. (a) Hydrate stability limits in pressure and temperature projection (solid). The first stage of isothermal pressure reduction, from initial condition of $278 \mathrm{~K}$ and 120 bar to hydrate stability limit for $278 \mathrm{~K}$ at 42.05 bar (dashed). Hydrate dissociation, and gas expansion to final condition of $274 \mathrm{~K}$ and 10 bar (dash dot). (b) Free energy changes along the changes in Figure 7a.

The released gas during pressure reduction from initial condition to stability limit pressure is calculated to $448.63 \mathrm{moles} / \mathrm{m}^{3}$ hydrate. The associated rearrangement of the hydrate involves a limited entropy change. The kinetics of these rearrangements, and the associated gas release, is uncertain and beyond the scope of this work since it will require a set of different fundamental approaches to address. Calculated proeprties of the initial system is given in Table 2 below. Table 3 list proeprties of the water phases for the residual thermodynamic calculation utilized in this work.

Table 2. Properties of initial hydrate and hydrate at stability limit for $278 \mathrm{~K}$.

\begin{tabular}{ccc}
\hline Properties & $\mathbf{T = 2 7 8} \mathbf{K}, \boldsymbol{P}=\mathbf{1 2 0}$ Bar & T278, $\boldsymbol{P}=\mathbf{4 2 . 0 5}$ Bar \\
\hline Free energy $(\mathrm{kJ} / \mathrm{mole}$ hydrate) & -46.3288 & -46.1894 \\
\hline Filling fraction in large & 0.9684 & 0.9164 \\
\hline Filling fraction in small & 0.9502 & 0.8723 \\
\hline Average MW $(\mathrm{Kg} / \mathrm{mole})$ & 0.01771 & 0.01774 \\
\hline Hydrate density $\left(\mathrm{Kg} / \mathrm{m}^{3}\right)$ & 911.97 & 904.79 \\
\hline Molar density $\left(\mathrm{moles} / \mathrm{m}^{3}\right)$ & $51,486.4$ & $51,037.8$ \\
\hline Gas in hydrate $\left(\mathrm{moles} / \mathrm{m}^{3}\right)$ & 7391.54 & 6942.90 \\
\hline
\end{tabular}

Table 3. Parameters for dimensionless chemical potential functions in Equation (29).

\begin{tabular}{ccccc}
\hline Water Phase, $\boldsymbol{m}$ & $\mathbf{a}_{\mathbf{0}}$ & $\mathbf{a}_{\mathbf{1}}$ & $\mathbf{a}_{\mathbf{2}}$ & $\mathbf{a}_{\mathbf{3}}$ \\
\hline Empty structure I & -21.3284 & -18.2744 & -2.0038 & 5.2190 \\
\hline Empty structure II & -21.3694 & -18.2196 & -1.8000 & 6.2719 \\
\hline Ice $(\mathrm{T}<273.15 \mathrm{~K})$ & -21.6937 & -18.8285 & -2.4347 & 0.1953 \\
\hline Liquid water $(\mathrm{T}>273.15 \mathrm{~K})$ & -21.6935 & -16.2933 & -2.0352 & 3.8636 \\
\hline
\end{tabular}

Some possible approaches for calculating the phase transition enthalpy changes are given by Kvamme [13,14] and Kvamme et.al. [30,39]. Going back to the original data from the simulations presented in fitted form in the paper by Kvamme and Tanaka [17] an alternative representation of the data can be presented by:

$$
\frac{\mu_{H_{2} \mathrm{O}}^{m}}{R T}=a_{0}^{m}+a_{1}^{m}\left[\left(\frac{273.15}{T}\right)-1\right]+a_{2}^{m}\left[\left(\frac{273.15}{T}\right)-1\right]^{2}+a_{3}^{m}\left[\left(\frac{273.15}{T}\right)-1\right]^{3}
$$


Some other properties along the temperature pressure stability limit curves are also fitted to the same type of function as Equation (29):

$$
f(T, P)=a_{0}^{m}+a_{1}^{m}\left[\left(\frac{273.15}{T(P)}\right)-1\right]+a_{2}^{m}\left[\left(\frac{273.15}{T(P)}\right)-1\right]^{2}
$$

Even if the polyonomial is a function of T, every $\mathrm{T}$ on the stability limit curve in 4 (a) is an implicit function of the conditions for hydrate $P, T$ stability limit. See Table 4 for parameters to Equation (30).

Table 4. Parameters for dimensionless chemical potential functions in Equation (30).

\begin{tabular}{cccc}
\hline$f(T, P)$ & $\mathbf{a}_{\mathbf{0}}$ & $\mathbf{a}_{\mathbf{1}}$ & $\mathbf{a}_{\mathbf{2}}$ \\
\hline$G^{\text {Hydrate }}\left(T, P, \vec{x}^{\text {Hydrate }}\right)(\mathrm{kJ} /$ mole hydrate $)$ & -46.1405 & 2.5418 & -20.5391 \\
\hline $\begin{array}{c}\Delta H^{\text {Hydrate, formation }}\left(T, P, \vec{x}^{\text {Hydrate }}\right. \\
(\mathrm{kJ} / \text { mole hydrate former })\end{array}$ & -56.9322 & -97.8273 & 691.3817 \\
\hline $\begin{array}{c}\text { Hydrate coordination number (average } \\
\text { number of water per hydrate former })\end{array}$ & 6.4518 & 6.5428 & 57.7907 \\
\hline
\end{tabular}

Hydrate dissociates in two different ways. If the kinetic dissociation rate, and the associated release rate of $\mathrm{CH}_{4}$, is slower than the kinetic rates of dissolving and distributing the released $\mathrm{CH}_{4}$ in the surrounding water then the free energy change of the dissociation is the free energy change related to the following phase transition:

$$
\left(n \mathrm{H}_{2} \mathrm{OCH}_{4}\right)^{\mathrm{Hydrate}} \rightarrow n \mathrm{H}_{2} \mathrm{O}^{a q .}+\mathrm{CH}_{4}^{a q .}
$$

This is at least dominating the initial stages of pressure reduction in which water is dragged in from surrounding parts of the formation. When the dissociation is fast, parts of the hydrate surface will be covered by gas bubbles, as also observed in model studies of $\mathrm{CO}_{2}$ exchange $[2,3,6]$. In both cases the hydrate dissociation will lead to a continuous replacement of the hydrate/liquid water interface. The difference is therefore essentially that the dissociation rate is higher for regions of direct contact between hydrate and liquid water. Regions covered by gas bubbles will involve that the water driving force is sublimation into gas bubble while $\mathrm{CH}_{4}$ driving force is difference in chemical potential between $\mathrm{CH}_{4}$ in hydrate and $\mathrm{CH}_{4}$ in gas bubble. In both cases, hydrate and water will continuously redevelop a new interface. The transport of $\mathrm{CH}_{4}$ through the interface layer will therefore be the same in both cases. Unlike nucleation of hydrate particles during formation there will as such not be the penalty of pushing away old phases during hydrate dissociation. But the free energy driving forces are different.

$$
\left(n \mathrm{H}_{2} \mathrm{OCH}_{4}\right)^{\mathrm{Hydrate}} \rightarrow n \mathrm{H}_{2} \mathrm{O}^{\text {aq. }}+\mathrm{CH}_{4}^{\text {gas }}
$$

Calculated free energy change for this phase transition in our example is then $-0.24 \mathrm{~kJ} / \mathrm{mole}$ hydrate. The corresponding Boltzmann factor for thermodynamic control of the phase transition in Classical nucleation theory is then 1.10. The maximum thermodynamic driving force for the phase transition according to (32) at initial temperature and stability limit pressure is $-0.05 \mathrm{~kJ} / \mathrm{mole}$. The associated Boltzmann factor is 1.02. In simple Classical Nucleation Theory (CNT) then the combined mass transport and thermodynamic control is:

$$
J=J_{0} e^{-\beta \Delta G}
$$

where $J_{0}$ is the mass transport flux for the dissociation. A model for the transport across the hydrate water interface was proposed by Kvamme et.al. [15] based on samplings from molecular dynamics simulations. Using this model, and a simple mass transport calculation, showed that is was possible to 
predict induction time for $\mathrm{CH}_{4}$ hydrate in an experimental plastic cell $[9,15]$. See Equation (31) below and associated parameters in Table 5. For $\mathrm{CH}_{4}$ we use $D_{\text {liquid }}$ equal to $5 \cdot 10^{-8} \mathrm{~m}^{2} / \mathrm{s}$.

$$
\left[\frac{D(z)_{j}}{D_{\text {liquid }, j}}\right]=9.5 \cdot 10^{-\sum_{i=1}^{9} a_{i}\left(a \tan \left[\left(0.5 z \frac{\pi}{2}\right) / 12\right]\right)^{i-1}}
$$

Table 5. Parameters for Equation (34).

\begin{tabular}{cccccc}
\hline $\boldsymbol{I}$ & Parameter & $\boldsymbol{i}$ & Parameter & $\boldsymbol{I}$ & Parameter \\
\hline 1 & 0.979242 & 4 & 171.673 & 7 & -9649.96 \\
2 & 15.5427 & 5 & 6.76975 & 8 & $14,779.7$ \\
3 & -88.5112 & 6 & 1939.55 & 9 & -7496.15 \\
\hline
\end{tabular}

Calculated critical radii for $\mathrm{CH}_{4}$ hydrate at two different temperatures are given in Figure 3a. The associated nucleation times are based on integration of Fick's law:

$$
t(R=12 A)-t(R=0 A)=\int_{C_{C_{4}}(R=0)}^{C_{C_{4}}(R=12)} \frac{\partial C_{C_{4}}(z)}{\left[-D_{C_{4}}(z) \frac{\partial^{2} C_{C_{4}}(z)}{\partial z^{2}}\right]}
$$

The concentration profiles for $\mathrm{CH}_{4}$ as a function of distance from the hydrate side of the interface to the liquid side of the interface is available from Kvamme [13,14] and Kvamme et.al. [28]. The diffusivity coefficient profile for $\mathrm{CH}_{4}$ is given by Equation (34), with parameters from Table 5. For $280 \mathrm{~K}$ and a stability limit pressure Figure 7a of 42.05 bar the enthalpy of hydrate dissociation is calculated to $55.0 \mathrm{~kJ} / \mathrm{mole}$ guest for $\mathrm{CH}_{4}$ hydrate. The calculated dissociation flux based on Equation (32) is $2.54 \times 10^{-5}$ moles $\mathrm{CH}_{4} / \mathrm{m}^{2}$.s for a $\mathrm{CH}_{4}$ concentration in surrounding water close to the hydrate stability concentration in Figure 2b. In practice, the capacity of the surrounding water to distribute released $\mathrm{CH}_{4}$ in water solution is the difference between Figure 2a and the concentration projection of Figure $3 \mathrm{a}$. The associated mass transport limited heat needed is therefore $1.40 \times 10^{-3} \mathrm{~kW} / \mathrm{m}^{2}$. The thermodynamic impact is calculated to range between 1.02 and 1.10 as discussed above. Using 1.10, then the heat flux needed to support transporting guest molecules from hydrate and dissociate the hydrate is $1.54 \cdot 10^{-3} \mathrm{~kW} / \mathrm{m}^{2}$. Note that these example values reflect guesses of a situation related to dynamic pressure reduction production, in which it is expected that background $\mathrm{CH}_{4}$ content in water surrounding the hydrate is high and other factors also reduce dissociation flux according to driving for between chemical potential of $\mathrm{CH}_{4}$ in hydrate and $\mathrm{CH}_{4}$ in surrounding liquid water. This is just an example used to illustrate that the drawback of pressure reduction is that the method does not address a kinetic bottleneck of transporting molecules across a water hydrogen bonded interface. This is in contrast to thermal stimulation and adding chemicals that breaks water hydrogen bonds.

For comparison of the span of hydrate dissociation fluxes that can be present, the maximum value of dissociation fluxes calculated in the example related to hydrate dissociation.

The estimated dissociation fluxes above, therefore, are smaller than those in the next section which are estimations of dissociation fluxes of hydrate in contact with inflow of water through fracture systems.

With the approximation of heat transport being represented by an "efficient" heat conductivity then Fourier's law is generally given by:

$$
\dot{Q}_{\text {conductivity }}=k \nabla T
$$

where the heat conductivity will vary during a production scenario. Hydrate saturation (volume per cent hydrate in pores) varies. But even in very closed reservoirs, like in permafrost regions in Alaska, it is hard to find any saturations higher than $85 \%$ and $75 \%$ as more typical. Offshore hydrates have 
generally lower hydrate saturations due to imperfection is sealing structures. Fracture systems that bring in seawater will lead to hydrate dissociation due to low content of $\mathrm{CH}_{4}$ in the incoming seawater, according to the stability limits in Figure 2a.

Heat conductivity will vary during hydrate production as the hydrate saturation gradually decreases. Heat conductivities that range from sediments with high hydrate saturation down to same sediments filled with liquid water are relevant for modeling purposes. But in a bigger picture it is also of interest to evaluate heat conductivities for liquid water, hydrate and sediments separately for the purpose of developing new theoretical models for heat conductivities in these systems of solid material and various water phases. Compared to heat conductivity in other phases, gas is a heat insulator and in a relative sense can often be approximated with zero heat conductivity.

Geo thermal gradients provide an initial temperature gradient from the top of a hydrate filled section down to the inlet of a production pipeline, whether this is a vertical completion or some version of horizontal completion. An additional temperature gradient will establish due to Joule-Thomson effects. These effects are very unique for each reservoir and for various stages of a production scenario. As such, it is not possible to develop some general conceptual correlations for this since it is a complex implicit dependency of mass and heat flow as well as dynamics of phase transitions. In general, a capable hydrate reservoir simulator can address this, provided that the simulator has sufficient rigorous treatment of thermodynamics and non-equilibrium phase transitions.

A simple one dimensional model of Fourier's law can be used for a qualitative analysis of the relative heat transport.

$$
\dot{Q}_{\text {conductivity }}=k \frac{d T}{d z}
$$

In which the unit of the thermal conductivity $k$ is $\mathrm{W} / \mathrm{m} \cdot \mathrm{K}$. An interesting ratio is, therefore, the heat needed by the mass transport limited process of transporting guest molecules from hydrate to surrounding phases:

$$
q_{r}=\frac{\dot{Q}_{m}}{\dot{Q}_{\text {conductivity }}}=\frac{J \Delta H}{k \frac{d T}{d z}}
$$

Heat conductivity is of course not the only way that heat is transported in a porous media but experimental data on heat transport in hydrate filled sediments is often approximated into a "lumped" heat conductivity coefficient. Similar for heat transport in hydrate reservoir simulators, which are frequently modelled as heat conductivity, with correlation for estimating heat conductivity from the pore filling volume fractions of the various phases, and the respective heat conductivities in these phases. For condensed phases these heat conductivities do not vary much with pressure. For liquid water the variation with pressure is practically zero while there is a very limited variation for hydrate due to the pressure dependency in filling fractions. This hydrate pressure dependency for heat conductivity is not very significant for non-polar guests but slightly higher for polar guest molecules like, for instance, $\mathrm{H}_{2} \mathrm{~S}$. In a pore scale model for heat conductivities during production there is of course also a need for heat conductivities for the gas phase. There are ways to calculate these but that is outside the scope of this paper. In many cases it would even be a fair approximation to approximate heat transport through gas as zero compared to the relatively high heat transport capability of minerals and water phases. On a larger scale there are hydrate-filled reservoirs that contain significant local volumes of separate hydrate phase. These types of reservoir hydrate fillings can typically build up as function of a balance between fractures that leads water into the hydrate sections from the ocean (vertically, horizontally and all possibilities in between), and fracture systems that bring in hydrate formers from below. Concentration of hydrate formers in incoming water is normally close to zero and in situ hydrate will therefore dissociate according to the stability limit window illustrated in Figure 3a. In certain cases of the balance between hydrate dissociation and formation of new hydrate the local flux inflow of gas may be large enough for the new hydrate to push aside sand and create hydrate filled "pockets" outside pore-filling hydrates. In Tables 6 and 7 we list some values for heat conductivities of 
various heat transport nedia containing water. Real sediments in real pilot plant experiments, like for instance the Ignik Sikumi [40] there is a variety of mineral types. In the long run we need to develop new correlations for heat transport through mixed media contining minerals, hydrate, liquid water and gas. For that reason we also list properties of water as well as dry minerals. See Tables 8 and 9 for heat conductivities of various individual phases/media involved. Some typical values of relevant geothermal gradients are listed in Table 10.

Table 6. Heat conductivities, $\mathrm{k}$, for various transport media with water in units of $\mathrm{W} / \mathrm{mK} \varphi$ is porosity. $\mathrm{C}$ is average mineral composition (when available) in terms of relative portion of well-defined minerals, or in terms of average atomistic composition. R denote specific remarks, in which $\mathrm{E}$ denote experimental values and $\mathrm{M}$ denote theoretical values used in modeling. Missing information is denoted by N/A. In the T, P columns specific temperatures are in Celsius and pressures are in MPa. For references that report several different conditions and/or gradient information the letter $\mathrm{S}$ is used and reader is directed to the original reference for details.

\begin{tabular}{|c|c|c|c|c|c|c|c|}
\hline Minerals & $\mathrm{C}$ & $\Phi$ & $\mathbf{T}$ & $\mathbf{P}$ & $\mathbf{k}$ & $\mathbf{R}$ & Ref. \\
\hline \multirow{5}{*}{ Quartz sand } & \multirow{5}{*}{ N/A } & \multirow{5}{*}{0.442} & 6.12 & 4.50 & \multirow{5}{*}{1.0} & \multirow{5}{*}{ E, M } & \multirow{5}{*}{ [41] } \\
\hline & & & 6.02 & 4.50 & & & \\
\hline & & & 5.14 & 4.50 & & & \\
\hline & & & 3.89 & 3.50 & & & \\
\hline & & & 7.78 & 5.50 & & & \\
\hline A porous medium & N/A & 0.3 & $\mathrm{~S}$ & S & 2.0 & M & {$[42]$} \\
\hline Porous shale & N/A & N/A & $S$ & $S$ & 1.0 & M & {$[42]$} \\
\hline \multirow{3}{*}{ Bentheim sandstone } & \multirow{3}{*}{$\begin{array}{c}95 \%-99 \% \text { quartz } \\
\text { content with traces of } \\
\text { the clay mineral } \\
\text { kaolinite }\end{array}$} & \multirow{3}{*}{0.23} & 4.00 & 3.96 & \multirow{3}{*}{0.5} & \multirow{3}{*}{ E, M } & \multirow{3}{*}{ [43] } \\
\hline & & & 4.00 & 3.89 & & & \\
\hline & & & 4.00 & 3.82 & & & \\
\hline \multirow{3}{*}{ Calcite and quartz } & $\begin{array}{c}3.6 \% \text { calcite, } 86.4 \% \\
\text { quartz in aquifers }\end{array}$ & 0.1 & \multirow{3}{*}{$S$} & \multirow{3}{*}{$S$} & \multirow{3}{*}{4.64} & \multirow{3}{*}{ M } & \multirow{3}{*}[44]{} \\
\hline & $\begin{array}{c}4 \% \text { calcite, } 95 \% \\
\text { quartz in caprocks }\end{array}$ & 0.01 & & & & & \\
\hline & $\begin{array}{l}3.8 \% \text { calcite, } 91.2 \% \\
\text { quartz in fracture }\end{array}$ & 0.05 & & & & & \\
\hline \multirow{3}{*}{ Quartz } & \multirow{3}{*}{ N/A } & 0.3 in aquifer & \multirow{3}{*}{$\mathrm{S}$} & \multirow{3}{*}{$S$} & \multirow{3}{*}{0.5} & \multirow{3}{*}{ M } & \multirow{3}{*}[45,46]{} \\
\hline & & $\begin{array}{l}0.03 \text { in cap } \\
\text { rock }\end{array}$ & & & & & \\
\hline & & $\begin{array}{l}0.5 \text { in } \\
\text { fracture }\end{array}$ & & & & & \\
\hline Granite & $\begin{array}{c}\mathrm{TiO}_{2}, \mathrm{Al}_{2} \mathrm{O}_{3}, \mathrm{MgO}, \\
\mathrm{FeOT}, \mathrm{CaO}, \mathrm{P}_{2} \mathrm{O}_{5} \\
\mathrm{~K}_{2} \mathrm{O} \text { and } 66.4-75.0 \% \\
\mathrm{SiO} 2\end{array}$ & $\begin{array}{l}\text { Varies from } \\
0.511-2.636 \%\end{array}$ & 25 & 0.1 & $2.12-3.12$ & $\mathrm{E}$ & [47] \\
\hline
\end{tabular}


Table 6. Cont.

\begin{tabular}{|c|c|c|c|c|c|c|c|}
\hline Minerals & $\mathrm{C}$ & $\Phi$ & $\mathrm{T}$ & $\mathbf{P}$ & $\mathbf{k}$ & $\mathbf{R}$ & Ref. \\
\hline Sandstone-1 & $\mathrm{N} / \mathrm{A}(1)$ & $5 \%$ & $0-150$ & \multirow{8}{*}{0.1} & $1.82-2.01$ & \multirow{8}{*}{$\mathrm{E}$} & \multirow{8}{*}[48]{} \\
\hline Limestone & $\mathrm{N} / \mathrm{A}(2)$ & $5 \%$ & $0-150$ & & $1.55-1.94$ & & \\
\hline Amphibolites & N/A (3) & $1 \%$ & $0-150$ & & $2.35-3.52$ & & \\
\hline Granulate & $\begin{array}{c}\text { Saxonian Granulate } \\
\text { Mountains, Germany, } \\
\text { quartz } 38 \% \text {, } \\
\text { pla-gioclase } 9 \%, \\
\text { K-feldspar } 47 \% \text {, } \\
\text { biotite } 1 \%, 4 \% \text { granite, } \\
\text { mixture of crystalline } \\
\text { and amorphous } \\
\text { structures }\end{array}$ & $1 \%$ & $0-150$ & & $1.77-2.06$ & & \\
\hline Pyroxene-granulate & $\begin{array}{c}\text { Saxonian Granulate } \\
\text { Mountains, Germany, } \\
\text { granite } 6 \% \text {, } \\
\text { clinopyroxene } 39 \% \text {, } \\
\text { plagioclase } 34 \% \text {, } \\
\text { non-transparent } \\
\text { minerals } 11 \% \text {, } \\
\text { orthopyroxene } 9 \% \text {, } \\
\text { ambibolb } 1 \%\end{array}$ & $1.2 \%$ & $0-150$ & & $2.40-2.46$ & & \\
\hline Siltstone & $\mathrm{N} / \mathrm{A}(4)$ & $1 \%-2 \%$ & $2-250$ & & $1.93-2.62$ & & \\
\hline Dolomite & N/A (5) & $1 \%-2 \%$ & $2-250$ & & 3.14 & & \\
\hline Sandstone-3 & $\mathrm{N} / \mathrm{A}(6)$ & $13 \%$ & $2-250$ & & $2.34-2.71$ & & \\
\hline Quartz & \multirow{11}{*}{ N/A } & \multirow{11}{*}{ N/A } & \multirow{11}{*}{$\mathrm{N} / \mathrm{A}$} & \multirow{11}{*}{ N/A } & 7.7 & \multirow{11}{*}{$\mathrm{E}$} & \multirow{11}{*}{ [49] } \\
\hline Feldspar & & & & & 2.3 & & \\
\hline Pyrite & & & & & 19.2 & & \\
\hline Calcite & & & & & 3.3 & & \\
\hline Dolomite & & & & & 5.3 & & \\
\hline Anhydrite & & & & & 6.3 & & \\
\hline Chlorite & & & & & 3.3 & & \\
\hline Kaolinite & & & & & 2.9 & & \\
\hline Smectite & & & & & 1.9 & & \\
\hline Illite & & & & & 1.8 & & \\
\hline Illite/smectite & & & & & 1.8 & & \\
\hline
\end{tabular}

Notes: All dry mineral thermal conductivity data are measured when air is filled in a porous medium. There is no paper measuring thermal conductivity in vacuum environment in the above table. The values of $\mathrm{T}$ and $\mathrm{P}$ are not all the environmental conditions for measuring thermal conductivity, some of which are the temperatures for the related hydrate experiments in these papers. 1. Aktash, Dagestan, Russia, borehole \#1, $2977 \mathrm{~m}$. 2. Soltangasha, Dagestan, Russia, borehole \#96, $201 \mathrm{~m}$. 3. Kola ultra-deep borehole, 10,000 m. 4. Dmitrievskoe, from oil-gas field, borehole \#D44, Dagestan, Russia, 4570-4574 m. 5. Dmitrievskoe, from oil-gas field, borehole \#D44, Dagestan, Russia, 4247-4248 m. 6. Solonchak, Dagestan, Russia, borehole \#34, $3941 \mathrm{~m}$. 
Table 7. Heat conductivities, $\mathrm{k}$, for various transport media with water in units of $\mathrm{W} / \mathrm{mK}$. $\varphi$ is porosity. $\mathrm{C}$ is average mineral composition (when available) in terms of relative portion of well-defined minerals, or in terms of average atomistic composition. $\mathrm{x}$ is liquid water composition. In some cases the listed value is an average composition and denoted in brackets. $\mathrm{R}$ denote specific remarks, in which $\mathrm{E}$ denote experimental values and $\mathrm{M}$ denote theoretical values used in modeling. Missing information is denoted by N/A. In the T, P columns specific temperatures are in Celsius and pressures are in MPa. For references that report several different conditions and/or gradient information the letter $\mathrm{S}$ is used and reader is directed to the original reference for details.

\begin{tabular}{|c|c|c|c|c|c|c|c|c|c|}
\hline \multicolumn{2}{|c|}{ Minerals } & $\mathrm{C}$ & $\varphi$ & $\mathbf{T}$ & $\mathbf{P}$ & $\mathbf{x}$ & $\mathbf{k}$ & $\mathbf{R}$ & Ref. \\
\hline \multirow{5}{*}{\multicolumn{2}{|c|}{ Quartz sand }} & \multirow{5}{*}{ N/A } & \multirow{5}{*}{0.442} & 6.12 & 4.50 & \multirow{5}{*}{$<0.274>$} & \multirow{5}{*}{2.1} & \multirow{5}{*}{$\mathrm{E}, \mathrm{M}$} & \multirow{5}{*}{ [41] } \\
\hline & & & & 6.02 & 4.50 & & & & \\
\hline & & & & 5.14 & 4.50 & & & & \\
\hline & & & & 3.89 & 3.50 & & & & \\
\hline & & & & 7.78 & 5.50 & & & & \\
\hline \multicolumn{2}{|c|}{ A porous medium } & N/A & 0.3 & $\mathrm{~S}$ & $\mathrm{~S}$ & N/A & 2.18 & M & [42] \\
\hline \multicolumn{2}{|c|}{ Porous shale } & N/A & N/A & N/A & N/A & $\mathrm{S}$ & 3.1 & M & [42] \\
\hline \multicolumn{2}{|c|}{$\begin{array}{l}\text { Construction sand with } \\
\text { quartz as the primary } \\
\text { component }\end{array}$} & N/A & 0.47 & 0 & 6.6 & N/A & 2.08 & $\mathrm{E}, \mathrm{M}$ & [46] \\
\hline \multirow{3}{*}{\multicolumn{2}{|c|}{ Bentheim sandstone }} & \multirow{3}{*}{$\begin{array}{c}95 \%-99 \% \text { quartz } \\
\text { content with traces } \\
\text { of the clay mineral } \\
\text { kaolinite }\end{array}$} & \multirow{3}{*}{0.23} & 4.00 & 3.96 & 0.45 & \multirow{3}{*}{3.1} & \multirow{3}{*}{$\mathrm{E}, \mathrm{M}$} & \multirow{3}{*}{ [43] } \\
\hline & & & & 4.00 & 3.89 & 0.50 & & & \\
\hline & & & & 4.00 & 3.82 & 0.44 & & & \\
\hline \multirow{3}{*}{\multicolumn{2}{|c|}{ Calcite and quartz }} & $\begin{array}{l}3.6 \% \text { calcite, } 86.4 \% \\
\text { quartz in aquifers }\end{array}$ & 0.1 & \multirow{3}{*}{$\mathrm{S}$} & \multirow{3}{*}{$\mathrm{S}$} & \multirow{3}{*}{ N/A } & \multirow{3}{*}{2.64} & \multirow{3}{*}{ M } & \multirow{3}{*}{ [44] } \\
\hline & & $\begin{array}{c}4 \% \text { calcite, } 95 \% \\
\text { quartz in caprocks }\end{array}$ & 0.01 & & & & & & \\
\hline & & $\begin{array}{l}3.8 \% \text { calcite, } 91.2 \% \\
\text { quartz in fracture }\end{array}$ & 0.05 & & & & & & \\
\hline \multirow{3}{*}{\multicolumn{2}{|c|}{ Quartz }} & \multirow{3}{*}{ N/A } & 0.3 in aquifer & \multirow{3}{*}{$\mathrm{S}$} & \multirow{3}{*}{$\mathrm{S}$} & \multirow{3}{*}{0.5} & \multirow{3}{*}{0.5} & \multirow{3}{*}{$\mathrm{M}$} & \multirow{3}{*}{$\begin{array}{l}{[45,} \\
46]\end{array}$} \\
\hline & & & 0.03 in cap rock & & & & & & \\
\hline & & & 0.5 in fracture & & & & & & \\
\hline Gra & nite & $\begin{array}{c}\mathrm{TiO}_{2}, \mathrm{Al}_{2} \mathrm{O}_{3}, \mathrm{MgO}, \\
\mathrm{FeO}^{\mathrm{T}}, \mathrm{CaO}, \mathrm{P}_{2} \mathrm{O}_{5} \\
\mathrm{~K}_{2} \mathrm{O} \text { and } \\
66.4-75.0 \% \mathrm{SiO}_{2}\end{array}$ & $\begin{array}{l}\text { Varies from } \\
0.511-2.636 \%\end{array}$ & 25 & 0.1 & $\begin{array}{l}\text { Varies from } 0 \\
\text { to } 1\end{array}$ & $2.99-3.62$ & $\mathrm{E}$ & [47] \\
\hline Sands & one-2 & N/A (1) & $16.2 \%$ & $2-150$ & 0.1 & N/A (water & $2.25-2.30$ & E & [48] \\
\hline Sands & one-3 & N/A (2) & $13 \%$ & $8-245$ & 0.1 & saturated sand & $3.41-3.81$ & & \\
\hline Mudstone & $\begin{array}{c}\text { Tertiary } \\
\text { mudstones }\end{array}$ & $\begin{array}{c}\text { sandy } \\
\text { mudstones, } \\
\text { claystones } \\
(26 \%-50 \%) \\
\text { andquartzite, clayey } \\
(16-45 \%) \\
\end{array}$ & $\begin{array}{c}\mathrm{N} / \mathrm{A} \\
\text { (can calculated } \\
\text { by the water }\end{array}$ & $22-38$ & 0.1 & $9 \%-42 \%$ & $0.79-1.14$ & $\mathrm{E}$ & [49] \\
\hline & $\begin{array}{l}\text { Sandy } \\
\text { siltstone }\end{array}$ & $\begin{array}{l}\text { Quartz }(13 \%-21 \%), \\
\text { feldspar and micain } \\
\text { a clayey matrix } \\
(50 \%-70 \%)\end{array}$ & content) & & & $11 \%-19 \%$ & $0.71-1.02$ & & \\
\hline & $\begin{array}{c}\text { fissile } \\
\text { mudstones }\end{array}$ & $\begin{array}{c}\text { clay }(30 \%) \text { quartz } \\
(42 \%)\end{array}$ & & & & $21 \%$ & $\begin{array}{l}0.92 \text { and } \\
1.04\end{array}$ & & \\
\hline
\end{tabular}

Notes: Some papers on hydrate do not give the thermal conductivity at different temperature and pressure, but use the same value. 1. Buinaks, Dagestan, Russia. 2. Solonchak, Dagestan, Russia, borehole \#34, $3941 \mathrm{~m}$. 
Table 8. Heat conductivity for liquid water (W/mK) [50]. Temperature in K.

\begin{tabular}{cc}
\hline $\mathbf{T}$ & $\mathbf{k}$ \\
\hline 274.15 & 0.5587 \\
\hline 275.15 & 0.5609 \\
\hline 276.15 & 0.5631 \\
\hline 277.15 & 0.5653 \\
\hline 278.15 & 0.5675 \\
\hline 279.15 & 0.5697 \\
\hline 280.15 & 0.5718 \\
\hline 281.15 & 0.5739 \\
\hline 282.15 & 0.5760 \\
\hline 283.15 & 0.5781 \\
\hline 284.15 & 0.5801 \\
\hline 285.15 & 0.5821 \\
\hline 286.15 & 0.5841 \\
\hline 287.15 & 0.5861 \\
\hline 288.15 & 0.5881 \\
\hline 289.15 & 0.5900 \\
\hline 290.15 & 0.5919 \\
\hline $0.1 M P$ & -0.6065
\end{tabular}

$T^{*}=T / 298.15, k^{*}=k(T) / k(298.15), k(298.15 \mathrm{~K}, 0.1 \mathrm{MPa})=0.6065 \pm 0.0036 \mathrm{Wm}^{-1} \mathrm{~K}^{-1}, k *=-1.48445+4.12292 T *$ $-1.63866 T^{* 2}$ for $274 \leq T \leq 370 \mathrm{~K}$.

Table 9. Heat conductivity for hydrate as separate phase without sediments. T, P columns specific temperatures are in Kelvin and pressures are in MPa.

\begin{tabular}{cccc}
\hline $\mathbf{P}$ & $\mathbf{T}$ & $\mathbf{k}$ & Ref. \\
\cline { 1 - 3 } 4.0 & $263.2-283.1$ & $0.4846-0.4953$ & \\
\cline { 1 - 3 } 6.0 & $263.2-279.2$ & $0.4851-0.4946$ & \\
\cline { 1 - 3 } 9.5 & $263.2-275.3$ & $0.4866-0.5467$ & \\
\cline { 1 - 3 } 6.6 & 273 & 0.575 & {$[46]$} \\
\hline 0.2 & 216 & 0.45 & {$[52]$} \\
\hline \multirow{2}{*}{6.6} & $263.06-277.87$ & Uncompacted, 0.334-0.381 & [53] \\
\cline { 1 - 3 } & & Compacted, 0.568-0.587 & \\
\hline $3.8-14.2$ & $261.5-277.4$ & $<0.68 \pm 0.01>$ & {$[54]$} \\
\hline 31.5 & $-20-15$ & $0.62 \pm 0.02$ & {$[55]$} \\
\hline
\end{tabular}


Table 10. Geothermal gradients.

\begin{tabular}{|c|c|c|}
\hline $\begin{array}{l}\text { Temperature Gradient } \\
\qquad(\mathrm{K} / \mathrm{m})\end{array}$ & $\mathbf{R}$ & Ref. \\
\hline 0.019 & water depth of $1344 \mathrm{~m}$ & [56] \\
\hline 0.0355 & / & [42] \\
\hline 0.03 & / & [42] \\
\hline $0.019 \pm 0.002$ & $\begin{array}{l}\text { at site } 17 \text {, water depth } 1150 \text { to } 1350 \mathrm{~m} \text {, } \\
\text { depth below seafloor range from } 0 \mathrm{~m} \text { to } \\
700 \mathrm{~m}\end{array}$ & [57] \\
\hline $0.090-0.110$ & Water depth range from $898 \mathrm{~m}$ to $2153 \mathrm{~m}$ & [58] \\
\hline $\begin{array}{l}0.04753 ; 0.04695 ; 0.04934 \\
0.06760 ; 0.04365\end{array}$ & $\begin{array}{l}5 \text { sites, water depth range from } 1105 \mathrm{~m} \\
\text { to } 1290 \mathrm{~m}\end{array}$ & [59] \\
\hline 0.055 & $\begin{array}{l}\text { a total depth of } 1225 \mathrm{~m}: 1000 \mathrm{~m} \text { water } \\
\text { depth, } 225 \mathrm{~m} \text { sediment depth }\end{array}$ & [60] \\
\hline $0.04 ; 0.032 ; 0.02$ & permafrost, in different possible depth & [61] \\
\hline $\begin{array}{c}0.035 \text { (in the model); } 0.043 ; \\
0.03 ; 0.036\end{array}$ & $\begin{array}{l}\text { HBL of the Shenhu area, L-Pad area, the } \\
\text { Prudhoe Bay, in the Mt Elbert area }\end{array}$ & [62] \\
\hline 0.036 & used in model & [45] \\
\hline
\end{tabular}

Some illustrations of Equation (38) is given in Table 11 based on some average values from Table 8 to Table 9.

Table 11. Relative heat transport rates $q_{r}$ for various transport mediums and various temperature gradients and some typical values for various media. All k-values in $\mathrm{W} / \mathrm{m} \cdot \mathrm{K}$.

\begin{tabular}{|c|c|c|c|c|c|}
\hline \multirow{2}{*}{$\begin{array}{l}\text { Transport } \\
\text { Medium }\end{array}$} & \multicolumn{5}{|c|}{$q_{r}$ for Various Temperature Gradients } \\
\hline & $\frac{d T}{d z}=0.04 \mathrm{~K} / \mathrm{m}$ & $\frac{d T}{d z}=0.07 \mathrm{~K} / \mathrm{m}$ & $\frac{d T}{d z}=0.09 \mathrm{~K} / \mathrm{m}$ & $\frac{d T}{d z}=0.12 \mathrm{~K} / \mathrm{m}$ & $\frac{d T}{d z}=0.15 \mathrm{~K} / \mathrm{m}$ \\
\hline $\begin{array}{l}\text { Liquid water, } \\
\mathrm{k}=0.56\end{array}$ & 0.022400 & 0.039200 & 0.050400 & 0.067200 & 0.084000 \\
\hline $\begin{array}{l}\text { Hydrate, } \\
\mathrm{k}=0.49\end{array}$ & 0.019600 & 0.034300 & 0.044100 & 0.058800 & 0.073500 \\
\hline $\begin{array}{c}\text { Water filled } \\
\text { sediments, } \\
\mathrm{k}=2.7\end{array}$ & 0.108000 & 0.189000 & 0.243000 & 0.324000 & 0.405000 \\
\hline $\begin{array}{l}\text { Hydrate filled } \\
\text { sediments, } \\
\mathrm{k}=2.5\end{array}$ & 0.100000 & 0.175000 & 0.225000 & 0.300000 & 0.375000 \\
\hline
\end{tabular}

\section{The Use of $\mathrm{CO}_{2}$}

As also discussed above, one of the critical limitations of the pressure reduction method is the lack of sufficient heating of the interface. Slow diffusion of $\mathrm{CH}_{4}$ though the water/hydrate interface is a dynamic bottleneck in dissociation of the hydrate. Any thermally based method is kinetically efficient because of the breaking of hydrogen bonds and loosening up of the hydrate/water interface structure. Direct addition of heat in the form of steam or hot water is not economically feasible. Other ways of adding heat has also been proposed but still remain to be proven economically and technically feasible. Other ways to break water hydrogen bonds are also well known from hydrate inhibition. Methanol is likely the most used thermodynamic hydrate inhibitor but any chemicals and salts that break hydrogen bonds will do the work of hydrate dissociation. But the cost is beyond any realistic economic feasibility relative to value of produced gas from hydrate. 
Another alternative, which is often misunderstood, is the use of $\mathrm{CO}_{2}$. Several research groups around the world have spent several years experimenting on the injection of $\mathrm{CO}_{2}$ into hydrate filled sediment models in laboratories. Few of these have been successful because injected $\mathrm{CO}_{2}$ will result in nucleation of new hydrate with the free water in the pores. These nucleation processes happens on a nano second time scale [13-15] (and references in these papers). This will rapidly lead to blocking of the sample and to extremely slow conversion from in situ $\mathrm{CH}_{4}$ hydrate to $\mathrm{CO}_{2}$ hydrate.

As a possible way to reduce this blocking the addition of nitrogen has been utilized by some research groups. Addition of $\mathrm{N}_{2}$ was also utilized in the Ignik Sikumi pilot plant test $[1,40]$. Limited amounts of $\mathrm{N}_{2}$ in $\mathrm{CO}_{2}$ will still make it possible to create new $\mathrm{CO}_{2}$ dominated hydrate together with free pore water. Another positive effect of adding limited amounts of $\mathrm{N}_{2}$ is the increase in gas permeability for the $\mathrm{CO}_{2} / \mathrm{N}_{2}$. However, $\mathrm{N}_{2}$ does not address the limitation of hydrate films and additional chemicals are needed to keep the water $/ \mathrm{CO}_{2}$ interface hydrate free. The theoretical study of Kvamme et. al. [28] provides some insight into how surfactants promote hydrate formation without blocking water $\mathrm{CO}_{2}$ interface. The most feasible mechanism for in situ $\mathrm{CH}_{4} / \mathrm{CO}_{2}$ swap does not actually involve direct contact with the $\mathrm{CH}_{4}$ hydrate. Formation of a new $\mathrm{CO}_{2}$ hydrate releases excess heat compared to necessary heat for $\mathrm{CH}_{4}$ hydrate dissociation $[13,14,30]$. This is also consistent with model studies using Phase Field Theory [2,3], which demonstrate a liquid water mass transport limited kinetic rate as long as free water is available around $\mathrm{CH}_{4}$ hydrate core. This liquid transport controlled process changes to a slow solid state controlled exchange when the free water is consumed. As also discussed by Kvamme [1] the high $\mathrm{N}_{2}$ content in the injection $\mathrm{CO}_{2} / \mathrm{N}_{2}$ gas mix used in the Ignik Sikimu $[1,40]$ might be an important reason for the limited efficiency observed in the pilot test.

Plots of stability limits in independent thermodynamic variables do not tell us anything about feasibilities in terms of energy, but since chemical potential of water and hydrate formers are used for constructing pressure temperature stability limits then Figure 8 and the comparison with experimental data give some model verification. Figure $8 \mathrm{~b}$ is the most interesting in terms of using $\mathrm{CO}_{2} / \mathrm{N}_{2}$ mixtures. Although it does not tell anything about the energies involved and the possible feasibility of using these mixtures less than $30 \% \mathrm{CO}_{2}$ may not be feasible. But as discussed above, the free energy change has to be feasible enough to facilitate the phase transition. And sufficient heat must be available to support the needed enthalpy of dissociation for the hydrate. In Figure 9 we plot the free energy changes associated with the hydrates along the curves in Figure $8 \mathrm{~b}$.

Figure 9 tells us that the formation of a new hydrate from injection gases with composition in the range of the $\mathrm{CO}_{2} / \mathrm{N}_{2}$ plots in Figure 9 will be more stable the in situ $\mathrm{CH}_{4}$ hydrate at same conditions. But Figure 9 does not tell if these phase transitions are possible in terms of all independent thermodynamic variables in the system. Since water is the dominating component than a first check would be to find out the maximum $\mathrm{N}_{2}$ content for which hydrate water chemical potential is lower than liquid water chemical potential. This has already been done by Kvamme [1] and $\mathrm{CO}_{2}$ less than roughly 25 mole\% in $\mathrm{CO}_{2} / \mathrm{N}_{2}$ mix is unlikely to make a new hydrate with free pore water. There is, however, another point that can make it possible to make hydrate from even more dilute mixtures. As also discussed by Kvamme [1], there will be selective adsorption of $\mathrm{CO}_{2}$ on the surface of liquid water prior to hydrate formation. i.e., the concentration of $\mathrm{CO}_{2}$ on the gas/water interface is likely to be significantly higher than the average gas concentration of $\mathrm{CO}_{2}$. Based on calculations of selective adsorption [1] of $\mathrm{CO}_{2}$ from $\mathrm{CO}_{2} / \mathrm{N}_{2}$ mixtures as pre-stages for hydrate formation, even $\mathrm{CO}_{2} / \mathrm{N}_{2}$ mixtures up to $35 \mathrm{~mole} \% \mathrm{~N}_{2}$ might be feasible. However, this also depends on low dosage additives that can keep the water/gas interface free of blocking hydrate [28]. 


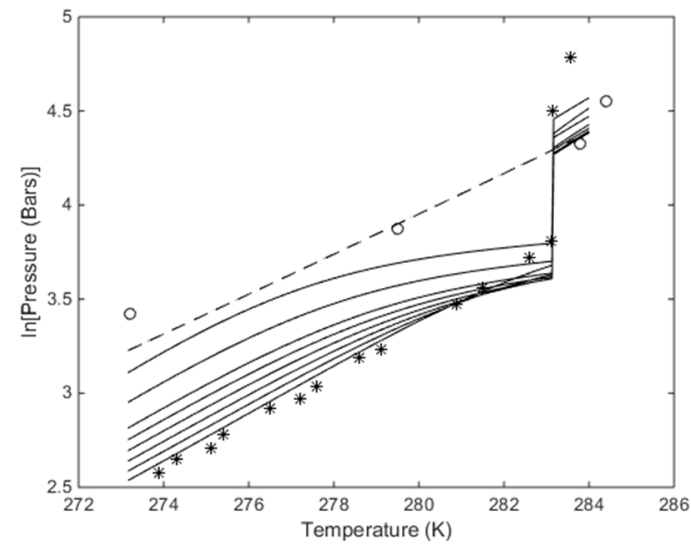

(a)

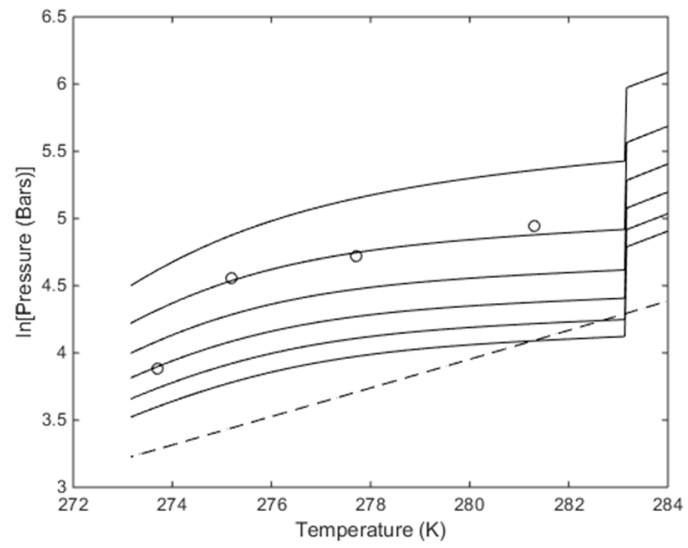

(b)

Figure 8. (a) Calculated stability limits for hydrate in temperature pressure projection of the hydrate stability window. Lowest solid curve is for pure $\mathrm{CO}_{2}$, followed by $95 \mathrm{~mole} \% \mathrm{CO}_{2}$, then $90 \mathrm{~mole} \% \mathrm{CO}_{2}$, then 85 mole $\% \mathrm{CO}_{2}$, then 80 mole $\% \mathrm{CO}_{2}$, then $75 \mathrm{~mole} \% \mathrm{CO}_{2}$, then $70 \mathrm{~mole} \% \mathrm{CO}_{2}$, then $60 \mathrm{~mole} \% \mathrm{CO}_{2}$ and upper solid curve for 50 mole $\% \mathrm{CO}_{2}$. The circles are experimental data from [63] for $50 \mathrm{~mole} \% \mathrm{CO}_{2}$, and as such to be compared to the highest solid curve. The stars are experimental data for pure $\mathrm{CO}_{2}$ [64] and as such comparable to the lowest solid curve. Dashed curve is for temperature pressure stability limits for $\mathrm{CH}_{4}$ hydrate. (b) Calculated stability limits for hydrate in temperature pressure projection of the hydrate stability window. Lowest solid curve is for $30 \mathrm{~mole} \% \mathrm{CO}_{2}$, followed by $25 \mathrm{~mole} \% \mathrm{CO}_{2}$, then 20 mole $\% \mathrm{CO}_{2}$, then 15 mole $\% \mathrm{CO}_{2}$, then 10 mole $\% \mathrm{CO}_{2}$ and upper solid curve for $5 \mathrm{~mole} \% \mathrm{CO}_{2}$. The circles are experimental data from [54] for $10 \mathrm{~mole} \% \mathrm{CO}_{2}$, and as such to be compared to the second solid curve from top. Dashed curve temperature pressure stability limits for $\mathrm{CH}_{4}$ hydrate.

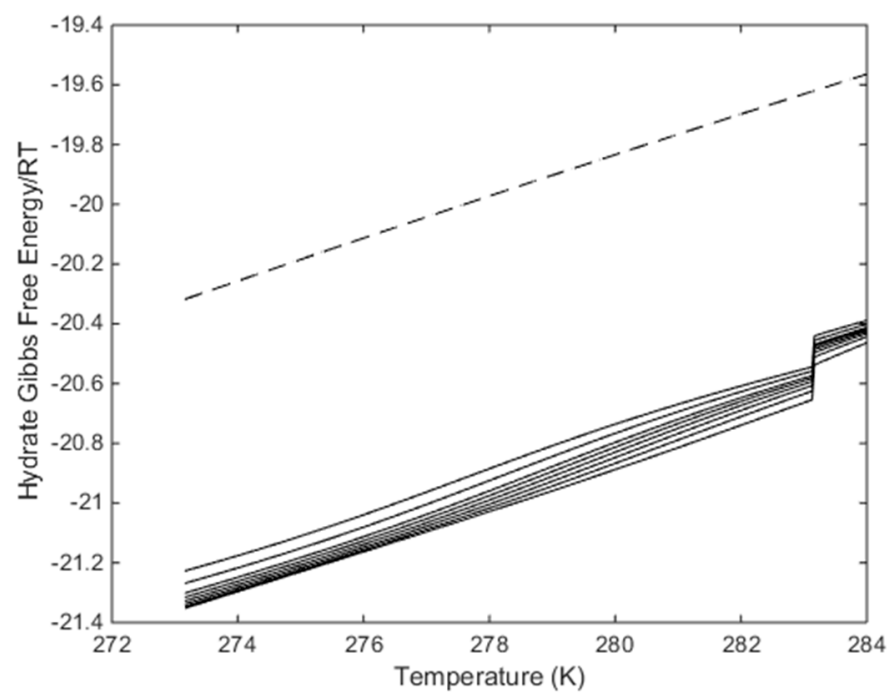

Figure 9. Calculated free energies for hydrate along the pressure temperature stability limits plotted in Figure 8 , in dimensionless unit. $\mathrm{R}$ is the universal gas constant and $\mathrm{T}$ is temperature in Kelvin. Lowest solid curve is for $95 \mathrm{~mole} \% \mathrm{CO}_{2}$, then $90 \mathrm{~mole} \% \mathrm{CO}_{2}$, then $85 \mathrm{~mole} \% \mathrm{CO}_{2}$, then $80 \mathrm{~mole} \% \mathrm{CO}_{2}$, then $75 \mathrm{~mole} \% \mathrm{CO}_{2}$, then $70 \mathrm{~mole} \% \mathrm{CO}_{2}$, then $60 \mathrm{~mole} \% \mathrm{CO}_{2}$ and upper solid curve for $50 \mathrm{~mole} \% \mathrm{CO}_{2}$. Dashed curve is free energy for pure $\mathrm{CH}_{4}$ hydrate along temperature pressure stability limits.

The considerations above are entirely based on aspects related to free energy changes and chemical potential driving forces for phase transitions. The second aspect on the feasibility of $\mathrm{CO}_{2} / \mathrm{N}_{2}$ and maximum percentage nitrogen is the associated needed heat for dissociation of the $\mathrm{CH}_{4}$ hydrate. Based on earlier studies $[14,30]$ it is known that the excess heat available from formation of hydrate from 
pure $\mathrm{CO}_{2}$ hydrate is in the order of $10 \mathrm{~kJ} /$ mole more than what is needed for dissociation of the in situ $\mathrm{CH}_{4}$ hydrate. The question is how added $\mathrm{N}_{2}$ changes the enthalpy of hydrate formation.

For this purpose we can examine specific cases of temperature and pressure. A first example is illustrated in Figures 8-10 below. Calculations are performed for a temperature of $274 \mathrm{~K}$ and 170 bars pressure. Note that pure $\mathrm{CO}_{2}$ is not able to fill the small cavity of structure I at liquid water conditions. There is some evidence that $\mathrm{CO}_{2}$ also can get trapped in small cavity at very low temperatures [65] but so far we have no evidence of $\mathrm{CO}_{2}$ filling in small cavities at liquid water hydrate-forming conditions. According to our studies using methods from classical statistical mechanics and quantum mechanics, we do not see any possibility for $\mathrm{CO}_{2}$ to stabilize the small cavity. This is important for the evaluation of changes in hydrate stability limits when $\mathrm{N}_{2}$ is added. The addition of $\mathrm{N}_{2}$ changes the chemical potential of $\mathrm{CO}_{2}$ in the mixture. On the other hand, $\mathrm{N}_{2}$ entrance in small cavities adds to the hydrate stability. In Figure 10 we plot the stability limit pressures for $274 \mathrm{~K}$ (Figure 10a) and stability limit temperatures for 170 bars pressure (Figure 10b). In Figure 9 we plot the enthalpies of hydrate formation as function of filling fractions for a pressure of 170 bars along the stability limit temperatures in Figure 10b.

The most relevant of these figures are Figures $8 a$ and $9 a$, although the transport of heat from forming $\mathrm{CO}_{2} / \mathrm{N}_{2}$ hydrate will lead to local temperature increase and consumption of heat for dissociation of $\mathrm{CH}_{4}$ hydrate.

With reference to Figure $11 \mathrm{~b}$ there is no change in gradient for the small fractions of $\mathrm{N}_{2}$. It is just an artefact of the applied resolution in that end of the mole-fraction $\mathrm{N}_{2}$. With a finer grid in that end it will show a smooth curve. The relevant information from Figure 11a is that even for a gas mixture of $30 \% \mathrm{~N}_{2}$ there is enough excess heat to dissociate in situ $\mathrm{CH}_{4}$ hydrate. The available excess heat; heat released from formation of hydrate from injection gas as compared to heat needed to dissociate $\mathrm{CH}_{4}$ hydrate, is reduced from roughly $10 \mathrm{~kJ} / \mathrm{mole}$ hydrate former down to roughly $8 \mathrm{~kJ} / \mathrm{mole}$. As compared to low temperature heat in the pressure reduction method this is substantial since the heat is directly generated in the pores during formation of the new hydrate.

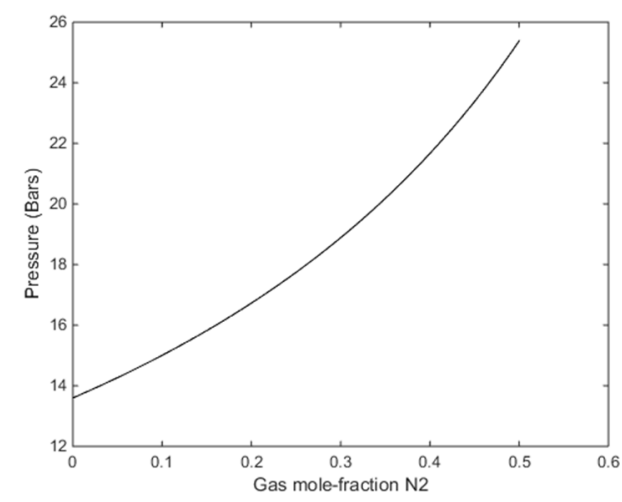

(a)

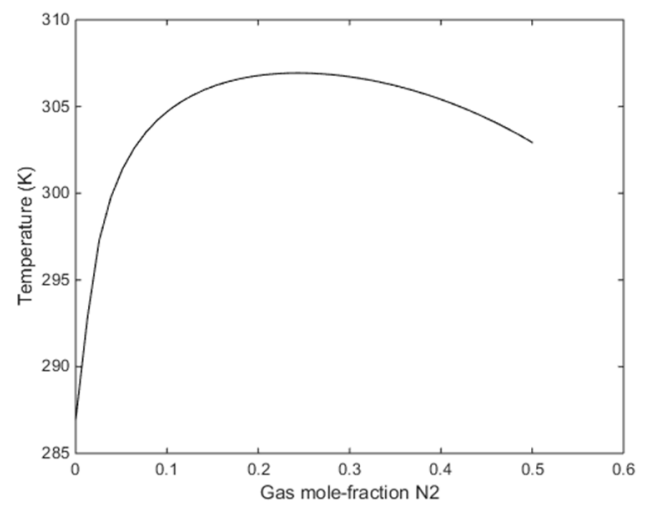

(b)

Figure 10. (a) Stability limit pressures for a temperature of $274 \mathrm{~K}$ as function of mole-fraction $\mathrm{N}_{2}$ in the injection gas mixture. (b) Stability limit temperatures as function of mole-fraction $\mathrm{N}_{2}$ in the injection gas mixture for a pressure of 170 bars. 


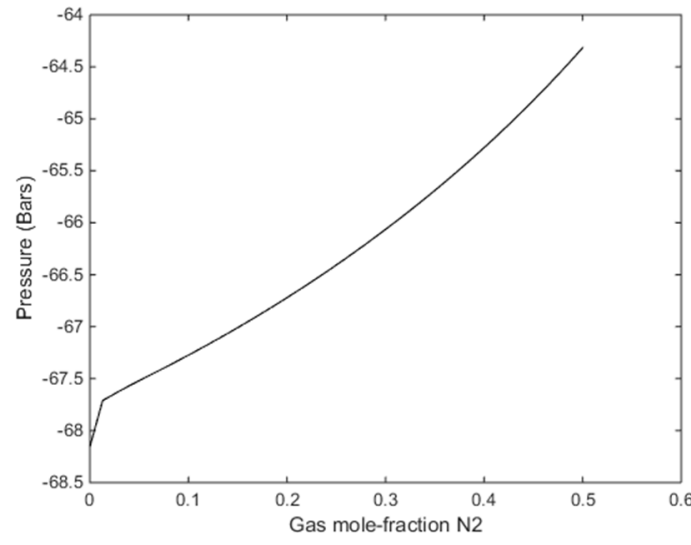

(a)

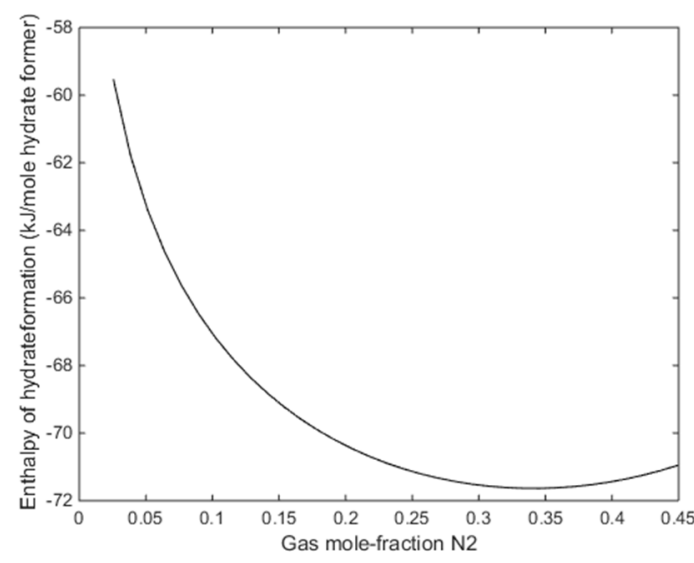

(b)

Figure 11. (a) Enthalpies of hydrate formation as function of mole-fraction $\mathrm{N}_{2}$ in injection gas for a temperature of $274 \mathrm{~K}$, along the stability limits in Figure 8a. (b) Enthalpies of hydrate formation as function of mole-fraction $\mathrm{N}_{2}$ in injection gas for a pressure of 170 bars, at stability limit temperatures of Figure $10 b$.

A final figure for this first example is the mole-fractions of guest fillings in the hydrate for the two cases in Figure 12a,b.

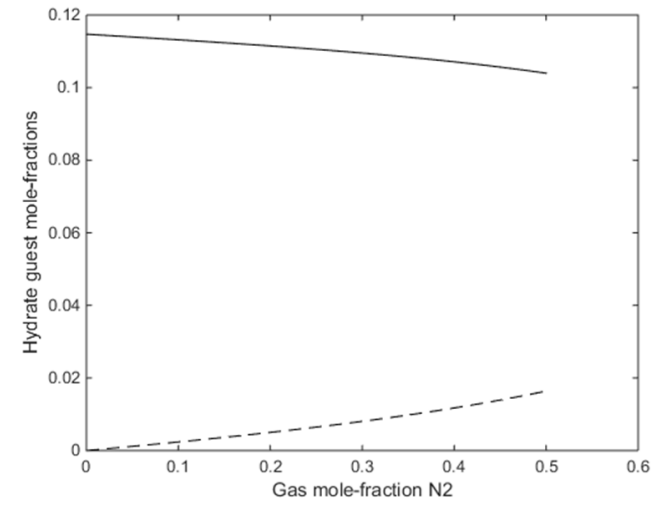

(a)

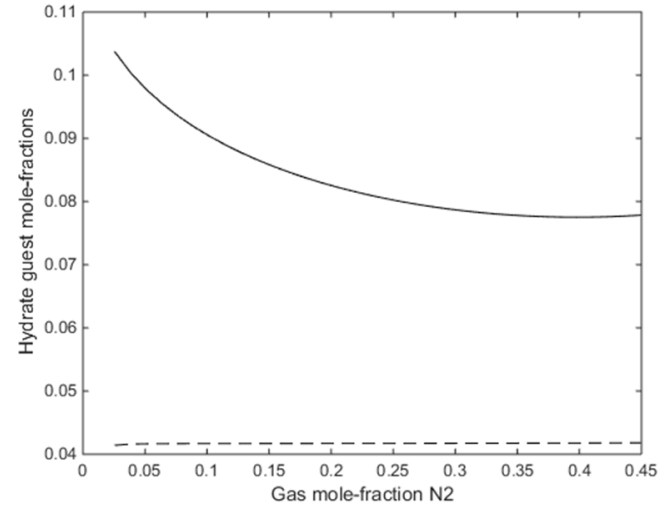

(b)

Figure 12. (a) Hydrate guest mole-fractions along the stability limits in Figure 11a. Solid curve is $\mathrm{CO}_{2}$ and dashed line is $\mathrm{N}_{2}$. (b) Hydrate guest mole-fractions along the stability limits in Figure 11a. Solid curve is $\mathrm{CO}_{2}$ and dashed line is $\mathrm{N}_{2}$.

In Figure 13, we plot stability limits pressure for $279 \mathrm{~K}$ as function of mole-fraction $\mathrm{N}_{2}$ in the gas, and associated enthalpies of hydrate formation. Also for this temperature there is sufficient available released heat form hydrate formation to ensure $\mathrm{CH}_{4}$ hydrate dissociation. 


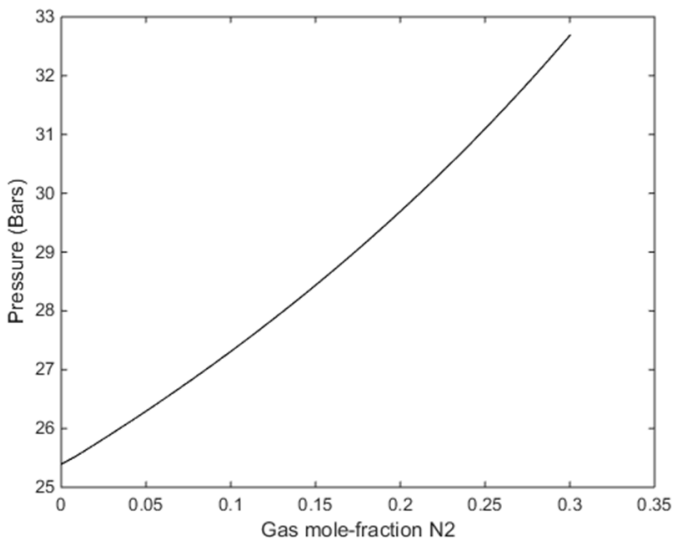

(a)

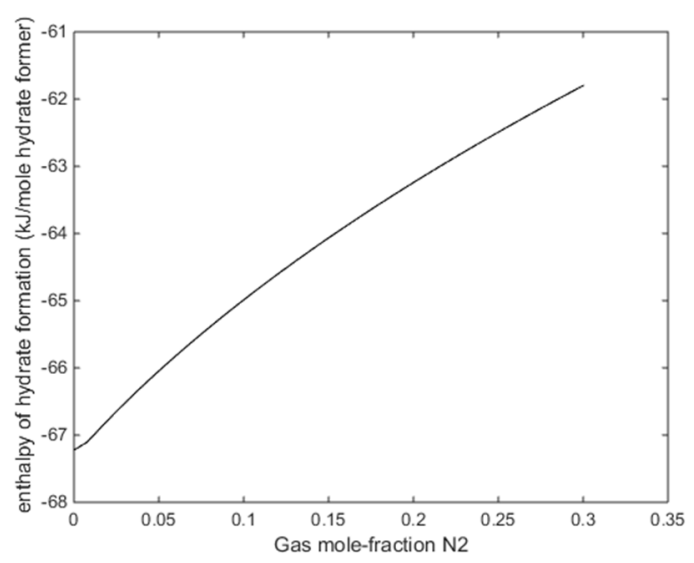

(b)

Figure 13. (a) Stability limits of pressure as function of mole fraction $\mathrm{N}_{2}$ in the gas for $279 \mathrm{~K}$ (b) Enthalpies of hydrate formation as function of mole-fraction $\mathrm{N}_{2}$ in injection gas for a temperature of $279 \mathrm{~K}$, along the stability limits in Figure 13a.

The more critical question is what happens when the temperature is reached at which pure $\mathrm{CO}_{2}$ would undergo a phase transition. From Figures 6 and 7 we know that this transition temperature for $\mathrm{CO}_{2}$ will also affect $\mathrm{CO}_{2} / \mathrm{N}_{2}$ mixture properties. In Figure 14a we plot enthalpies of hydrate formation as function of mole-fraction $\mathrm{N}_{2}$ along pressure stability limits for $284 \mathrm{~K}$. In Figure 14b, we plot enthalpies of hydrate formation for $\mathrm{CH}_{4}$ hydrate as function of temperature, along the pressure temperature stability limits. Comparing the values from Figure 14a with the enthalpies of $\mathrm{CH}_{4}$ hydrate formation at $284 \mathrm{~K}$ for $284 \mathrm{~K}$, it can be observed that there is still a net difference between formation of hydrate from $\mathrm{CO}_{2} / \mathrm{N}_{2}$ mixture, and formation enthalpy for $\mathrm{CH}_{4}$ hydrate in the order of $4 \mathrm{~kJ} / \mathrm{mole}$ hydrate former [14].

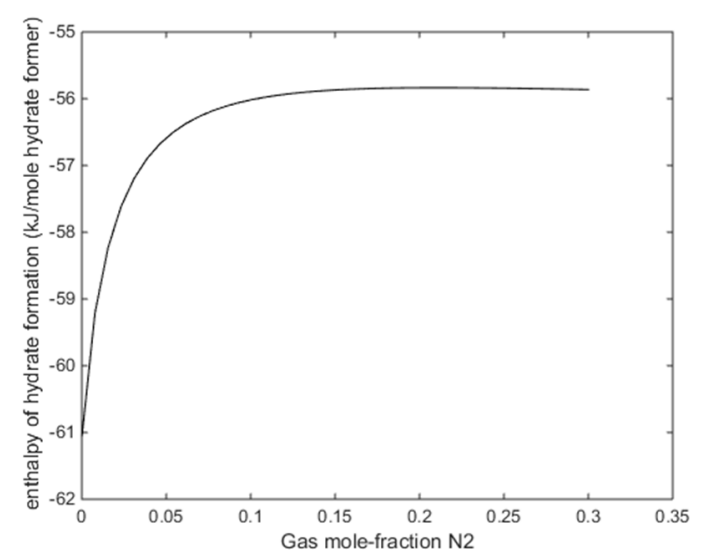

(a)

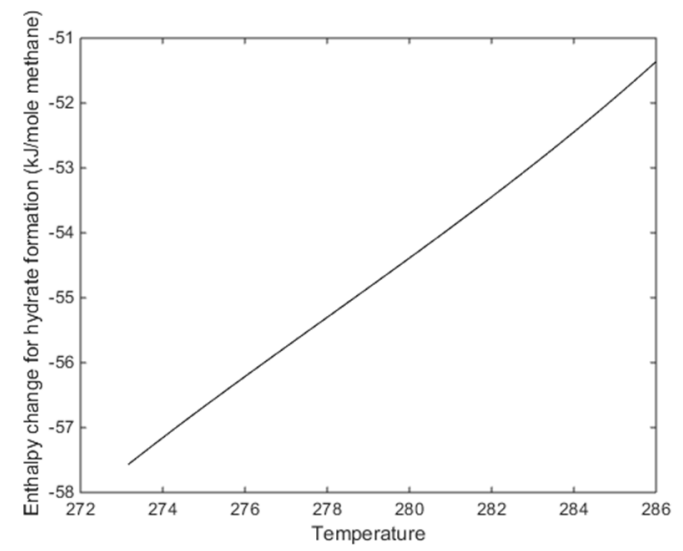

(b)

Figure 14. (a) Enthalpies of hydrate formation as function of mole-fraction $\mathrm{N}_{2}$ in the gas for a temperature of $284 \mathrm{~K}$ along the hydrate stability limit pressures. (b) Enthalpies of hydrate formation for $\mathrm{CH}_{4}$ hydrate as function of temperature along $\mathrm{CH}_{4}$ hydrate temperature pressure stability limits.

\section{Offshore Hydrates, Pockmarks and Relevance for Hydrate Production}

As discussed elsewhere, hydrate in sediments are not generally stale in sediments. They reside in a stationary balance between inflow of new hydrocarbons through fracture systems from below, which generates new hydrate, and inflow of seawater trough fracture systems which leads to hydrate dissociation according to Figure 3a. The tighter the sealing (clay, shale) of the hydrate section, the higher the hydrate saturation if the supply of hydrocarbons is sufficient. 
From a hydrate production point of view this is interesting for two reasons. The first of these is that the average hydrate saturation is highly dependent on the distribution of fracture systems that results in inflow of seawater into the hydrate-filled sections, and the associated flux rates. The second reason is that pressure reduction does not result in high enough temperatures to break the hydrogen bonded structure of the interface, as discussed earlier. Dissociation of hydrate in chemical potential gradients of hydrate guest molecules is, therefore, a significant dissociation mechanism for the hydrate during pressure reduction method for hydrate production.

In many cases the number of pockmarks and associated methane leakage fluxes can be the first indicator of the dynamics of the hydrate system. And frequently it is so that a high number of pockmarks that leaks methane indicate low average hydrate saturation and corresponding limited commercial value. One example is the Nyegga area offshore Norway, for which the average hydrate saturation is estimated to vary between $7 \%$ and $15 \%[66,67]$ (and references in these). An example from offshore China is reported by Luo et al. [68], which is very detailed in geochemical analysis, and corresponding estimates of methane fluxes. This study does not, however, contain enough information to estimate hydrate saturations and methane hydrate production potential.

Unlike pressure reduction hydrate production the background $\mathrm{CH}_{4}$ concentration in the water that leaks in to hydrate-filled sediments through fractures are expected to have a fairly low $\mathrm{CH}_{4}$ concentration. The salinity of pore water surrounding the hydrate may be different from incoming salinity. The initial $\mathrm{CH}_{4}$ in the water surrounding hydrate in the pores is very sensitive to the dynamic situation of the reservoir, i.e., dynamics of new hydrate formation and dynamics of hydrate dissociation. For the purpose of this paper, and in the absence of detailed data for specific cases, we just illustrate the sensitivity of hydrate dissociation fluxes on background concentration of $\mathrm{CH}_{4}$ and diffusivity on hydrate side of the interface. Some example values are listed in Table 12 below.

Table 12. Calculated hydrate dissociation fluxes in gradients of chemical potentials between $\mathrm{CH}_{4}$ in hydrate and $\mathrm{CH}_{4}$ in surrounding water.

\begin{tabular}{ccccc}
\hline \multirow{2}{*}{$\begin{array}{c}\text { Mole Fraction } \mathrm{CH}_{\mathbf{4}} \text { in } \\
\text { Liquid Water }\end{array}$} & \multicolumn{4}{c}{ Dissociation Flux $\left(\right.$ Moles $\left.\mathbf{C H}_{\mathbf{4}} / \mathbf{m}^{\mathbf{2}} \cdot \mathbf{s}\right)$ for Various Diffusivity Coefficients $\left(\mathbf{m}^{\mathbf{2}} / \mathbf{s}\right)$ at } \\
\cline { 2 - 5 } & $\mathbf{D}_{\mathbf{H}}=\mathbf{1 . 0} \times \mathbf{1 0}^{-\mathbf{1 2}}$ & $\mathbf{D}_{\mathbf{H}}=\mathbf{1 . 0} \times \mathbf{1 0}^{-\mathbf{1 3}}$ & $\mathbf{D}_{\mathbf{H}}=\mathbf{1 . 0} \times \mathbf{1 0}^{-\mathbf{1 4}}$ & $\mathbf{D}_{\mathbf{H}}=\mathbf{1 . 0} \times \mathbf{1 0}^{\mathbf{- 1 5}}$ \\
\hline $\mathrm{X}_{\mathrm{CH} 4}=1.0 \times 10^{-6}$ & 8.4016 & 0.8402 & 0.0840 & 0.0084 \\
\hline $\mathrm{X}_{\mathrm{CH} 4}=5.0 \times 10^{-6}$ & 6.9113 & 0.6911 & 0.0691 & 0.0069 \\
\hline $\mathrm{X}_{\mathrm{CH} 4}=1.0 \times 10^{-5}$ & 6.3552 & 0.6355 & 0.0636 & 0.0064 \\
\hline $\mathrm{X}_{\mathrm{CH} 4}=5.0 \times 10^{-5}$ & 5.2014 & 0.5214 & 0.0521 & 0.0052 \\
\hline
\end{tabular}

Hydrate dissociation towards water which is under saturated with hydrate former is also relevant for seafloor depths and local temperatures inside hydrate formation conditions. The source of the seeps can be hydrocarbon hydrates, but also ordinary seeps of hydrocarbons that enter seafloor conditions of hydrate formation. This generates a dynamically complex situation in which hydrate forms from below and dissociates towards seawater on top. Dissociation towards seawater in chemical gradients of $\mathrm{CH}_{4}$ in the seawater is likely the simplest of all the complex geo bio reactions and associated systems related to these seafloor hydrates. One of the challenges is that the thermodynamic properties of $\mathrm{CH}_{4}$ relevant for biological consumption are not known. Molecular modelling can be a toolbox for estimation of $\mathrm{CH}_{4}$ chemical potential relevant for the adsorption on various bio organisms prior to reaction with the bacteria. These aspects are very far from the scope of this work but feasible in future projects related to global gas seeps.

\section{Discussion}

Strategies for hydrate production have frequently been evaluated based on pressure temperature projections of the hydrate stability limits without more detailed thermodynamic calculations. One 
drawback of this is that the evaluation does not really take into account the strong water hydrogen bonds that keep the hydrate together, and the associated interface of structured water between hydrate and liquid water. This interface is a bottleneck [69] for transporting hydrate formers from the hydrate and into a gas or solution in surrounding water. Therefore, it is necessary to use a multi-scale dynamic analysis. The phase transition is nano scale, and is connected to pore scale level and fluid dynamics, as well as thermodynamic interactions between hydrate, liquid water, gas and mineral surfaces. On a higher scale, all the pores are connected in a reservoir model. We have not discussed the reservoir level here but the only hydrate non-equilibrium reservoir simulator is in development for implementation of the results discussed in this work. See for instance [70] and the papers included in the thesis for discussion of the RetrasoCodeBright (RCB) hydrate reservoir simulator.

A systematic analysis of the feasibility of various production methods for hydrate needs to evaluate if the method is able supply energy of a level needed to break hydrogen bonds. The next step will be to evaluate the thermodynamics of the proposed method. In this step, the free energy change involved is the key thermodynamic property related to the phase transition. But free energy change is fundamentally linked to enthalpy change for the phase transition by fundamental thermodynamic relationships. The necessary dissociation enthalpy must be supplied, and the thermodynamic calculations have to be consistent due to the implicit relationship between free energy and enthalpy.

In this work we have used examples to calculate two different production schemes. Pressure reduction gives a limited free energy change. Associated heat supply can be extracted from surroundings due to geothermal gradients and established temperature differences due to gas expansion during production. These temperature gradients are unique for every reservoir and local production conditions but it has never been verified that sufficient temperature gradients can be established, and maintained over time, to ensure realistic commercial production rates from hydrate. Other associated problems are the production of water and sand. Experimental studies of pressure reduction are frequently reported as isothermal experiments and as such have limited value since heat is supplied by the coolant system that keeps the temperature constant.

Thermal stimulation in the form of steam or hot water can be technically efficient although much heat is lost to minerals and sections of the reservoir which is not relevant for the production section. However, it will certainly break hydrogen bonds. Economically it is likely not feasible unless waste heat is available close by. Even heat sources of 50 degrees $C$ or even 40 degrees $C$ which may be hard to make efficient use of will have effect on the water hydrogen bonding structures in the hydrate and interface between hydrate and surrounding water. Other forms of heating are also possible but it is still a challenge to add heat efficiently at the right locations. This is certainly a problem if limited heat is used to assist pressure reduction method. Where should heat be supplied? Reformation of hydrates is possible many places in the producing section. And the mineral surfaces in the pore walls will act as hydrate catalysts all over the reservoir where temperatures and pressures facilitate hydrate formation.

The more novel technology of using $\mathrm{CO}_{2}$ has frequently also been misunderstood for several reasons. One misunderstanding is a discussion of the method based on independent thermodynamic variables ( $\mathrm{P}, \mathrm{T}$ projection of hydrate stability limits) rather than free energies. For some regions of temperatures the hydrate stability limits for $\mathrm{CH}_{4}$ hydrate is lower than those for $\mathrm{CO}_{2}$ hydrate. However, free energy calculations based on residual thermodynamics (ideal gas as reference for all components in all phases) shows that free energy for $\mathrm{CO}_{2}$ hydrate is more than roughly $2 \mathrm{~kJ} /$ mole hydrate more stable than $\mathrm{CH}_{4}$ hydrate. Another misunderstanding is related to the formation of blocking $\mathrm{CO}_{2}$ hydrate films. Injected $\mathrm{CO}_{2}$ forms new $\mathrm{CO}_{2}$ hydrate with free pore water. This hydrate nucleates on a nano-second time scale [13-15,69] and rapidly blocks the flow. During the latest decade a lot of efforts have been made on adding $\mathrm{N}_{2}$ to the $\mathrm{CO}_{2}$ in order to reduce blocking and increase injection gas permeability. Much of this work, including the Ignik Sikumi pilot, has been done without reflection on thermodynamic consequences. In this work we have systematically investigated the impact of adding various amounts of $\mathrm{N}_{2}$ on free energy of phase transitions and associate enthalpy changes. Based on free energy changes alone the creation of a new hydrate from $\mathrm{CO}_{2} / \mathrm{N}_{2}$ mix is feasible up to roughly $30 \%$ 
$\mathrm{N}_{2}$ but free energy gradients in all directions of independent thermodynamic variables are additional constraints of the free energy changes. See Equation (27). As discussed by Kvamme [1], the chemical potential of water in hydrate has to be lower that chemical potential of surrounding liquid water. If this water is pure water then the maximum $\mathrm{N}_{2}$ fraction might be $25 \mathrm{~mole} \%$. Selective adsorption of $\mathrm{CO}_{2}$ on liquid water [1] can increase this number, while solution of $\mathrm{CO}_{2}$ into liquid water point in the direction of less $\mathrm{N}_{2}$, even though some of the dissolved $\mathrm{CO}_{2}$ can form hydrate (see Figure 3a).

Associated enthalpy change related to the formation of hydrate from $\mathrm{CO}_{2} / \mathrm{N}_{2}$ mixtures shows that the excess released enthalpy relative to what is needed for dissociation is reduces to between 8 and $4 \mathrm{~kJ} / \mathrm{mole}$ hydrate depending on region of temperature. $\mathrm{CO}_{2}$ has a phase transition between 283 and $284 \mathrm{~K}$, and the reduction in excess enthalpy occurs after this phase transition. But even $4 \mathrm{~kJ} / \mathrm{mole}$ hydrate is substantial, and it is a highly directed heat release during formation of new hydrate in the pores containing the in situ $\mathrm{CH}_{4}$ hydrate. To our knowledge there are no experimental data for enthalpies of hydrate formation. The scatter in experimental values for simple pure $\mathrm{CO}_{2}$ hydrate and $\mathrm{CH}_{4}$ hydrate respectively is not very promising on the experimental side and the reasons are discussed elsewhere $[14,30,71]$. The impact of $\mathrm{CO} 2$ on enthalpies of hydrate dissociation seems realistic in terms of $\mathrm{N}_{2}$ filling in small cavities.

It is hard to find hydrates in nature with higher saturations than $75 \%$. In Ignik Sikumi, roughly $15 \%$ of the pore volume was interpreted as free water. There is available free water for formation of new hydrate, and dissociation of $\mathrm{CH}_{4}$ hydrate. Some of the $\mathrm{N}_{2}$ will also enter new hydrate, mostly through some filling in small cavities.

Due to the front of the new hydrate, released $\mathrm{CH}_{4}$ is likely to find its own pathways away from the new hydrate, which facilitate a collection of slightly lower pressure than local pressure in the reservoir.

\section{Conclusions}

Far too many studies related to evaluations of hydrate production strategies have been based on studies of independent thermodynamic variables, rather than actual thermodynamic calculations. The use of residual thermodynamics for all components in all phases, including hydrate, opens the way for consistent evaluations of phase stabilities as well as calculations of the relevant thermodynamic changes associated with hydrate phase transitions. Since hydrates cannot be in thermodynamic equilibrium in sediments, it is necessary to investigate hydrate stability limits in more variables that temperature and pressure. Hydrate stability limits towards surrounding liquid water is one of these which can be important for hydrate production. Another one is the impact of mineral surfaces on hydrate nucleation as mechanisms for hydrate formation and reformation.

The pressure reduction method involves fairly limited changes in free energies. With limited temperature gradients towards the surrounding formation it is a challenge related to heat transport aspects. However, low temperature heat is also a limitation in the dynamics of the hydrate phase transition. Strong hydrogen bonds in hydrate, and associated hydrogen bond structures in the interface between hydrate and liquid water, are a kinetic bottleneck.

The use of $\mathrm{CO}_{2}$ with addition of $\mathrm{N}_{2}$ have also been evaluated in terms of thermodynamics and it is concluded that addition of less than $30 \mathrm{~mole} \% \mathrm{~N}_{2}$ might be feasible, both in terms of free energy changes and enthalpy release during formation of $\mathrm{CO}_{2}$-dominated mixed $\mathrm{CO}_{2} / \mathrm{N}_{2}$ hydrate.

Author Contributions: All authors have contributed on conceptualization. All authors have read and agreed to the published version of the manuscript.

Funding: National Key Research and Development Program (No. 2018 YFC0310203 and No. 2016YFC0304008).

Acknowledgments: The research was supported by the National Key Research and Development Program (No. 2018YFC0310203 and No. 2016YFC0304008), Strategic Research Program of Chinese Academy of Engineering in Science and Technology Medium and Long-Term Development Strategy Research Field (No. 2017-ZCQ-5), Basic Applied Research Key Projects of Science and Technology Department of Sichuan Province (No. 2019YJ0419).

Conflicts of Interest: The authors declare no conflict of interest. 


\section{References}

1. Kvamme, B. Thermodynamic limitations of the $\mathrm{CO}_{2} / \mathrm{N}_{2}$ mixture injected into $\mathrm{CH}_{4}$ hydrate in the Ignik Sikumi field trial. J. Chem. Eng. Data 2016, 61, 1280-1295. [CrossRef]

2. Baig, K. Nano to Micro Scale Modeling of Hydrate Phase Transition Kinetics. Ph.D. Thesis, University of Bergen, Bergen, Norway, 2017.

3. Baig, K.; Kvamme, B.; Kuznetsova, T.; Bauman, J. The impact of water/hydrate film thickness on the kinetic rate of mixed hydrate formation during $\mathrm{CO}_{2}$ injection into $\mathrm{CH}_{4}$ hydrate. AIChE J. 2015, 61, 3944-3957. [CrossRef]

4. Kvamme, B.; Graue, A.; Aspenes, E.; Kuznetsova, T.; Gránásy, L.; Tóth, G.; Pusztai, T.; Tegze, G. Kinetics of solid hydrate formation by carbon dioxide: Phase field theory of hydrate nucleation and magnetic resonance imaging. Phys. Chem. Chem. Phys. 2004, 6, 2327-2334. [CrossRef]

5. Tegze, G.; Pusztai, T.; Tóth, G.; Gránásy, L. Multiscale approach to $\mathrm{CO}_{2}$ hydrate formation in aqueous solution: Phase field theory and molecular dynamics. Nucleation and growth. J. Chem. Phys. 2006, 124, 234710. [CrossRef] [PubMed]

6. Qasim, M. Microscale Modeling of Natural Gas Hydrates in Reservoirs. Ph.D. Thesis, University of Bergen, Bergen, Norway, 2012.

7. Svandal, A. Modeling Hydrate Phase Transitions Using Mean-Field Approaches. Ph.D. Thesis, University of Bergen, Bergen, Norway, 2006.

8. Kvamme, B.; Kuznetsova, T.; Kivelæ, P.H.; Bauman, J. Can hydrate form in carbon dioxide from dissolved water? Phys. Chem. Chem. Phys. 2013, 15, 2063-2074. [CrossRef]

9. Kvamme, B.; Graue, A.; Buanes, T.; Kuznetsova, T.; Ersland, G. Storage of $\mathrm{CO}_{2}$ in natural gas hydrate reservoirs and the effect of hydrate as an extra sealing in cold aquifers. Int. J. Greenh. Gas Control 2007, 1, 236-246. [CrossRef]

10. Buanes, T. Mean-Field Approaches Applied to Hydrate Phase Transition. Ph.D. Thesis, University of Bergen, Bergen, Norway, 2006.

11. Buanes, T.; Kvamme, B.; Svandal, A. Two approaches for Modelling Hydrate Growth. J. Math. Chem. 2009, 46, 811-819. [CrossRef]

12. Buanes, T.; Kvamme, B.; Svandal, A. Computer Simulation of CO2 Hydrate Growth. J. Cryst. Growth 2006, 287, 491-494. [CrossRef]

13. Kvamme, B. Environmentally friendly production of methane from natural gas hydrate using carbon dioxide. Sustainability 2019, 11, 1964. [CrossRef]

14. Kvamme, B. Enthalpies of hydrate formation from hydrate formers dissolved in water. Energies 2019, 12, 1039. [CrossRef]

15. Kvamme, B.; Coffin, R.B.; Wei, N.; Zhou, S.; Zhao, J.; Li, Q.; Saeidi, N.; Chien, Y.-C.; Dunn-Rankin, D.; Sun, W.; et al. Stages in dynamics of hydrate formation and consequences for design of experiments for hydrate formation in sediments. Energies 2019, 12, 3399. [CrossRef]

16. van der Waals, J.H.; Platteeuw, J.C. Clathrate sohtions. Adv. Chem. Phys. 1959, 2, 1-57.

17. Kvamme, B.; Tanaka, H. Thermodynamic stability of hydrates for ethylene, ethane and carbon dioxide. J. Phys. Chem. 1995, 99, 7114-7119. [CrossRef]

18. Sloan, E.D.; Koh, C.A. Clathrate Hydrates of Natural Gases, 3rd ed.; CRC Press: Boca Raton, FL, USA, 2007.

19. Kvamme, B.; Førrisdahl, O.K. Polar guest-molecules in natural gas hydrates. Fluid Ph. Equilib. 1993, 83, 427-435. [CrossRef]

20. Kvamme, B.; Lund, A. The influence of gas-gas interactions on the Langmuir-constants for some natural gas hydrates. Fluid Ph. Equilib. 1993, 90, 15-44. [CrossRef]

21. Kvamme, B.; Aromada, S.A. Risk of hydrate formation during processing and transport of Troll gas from the North Sea. J. Chem. Eng. Data 2017, 62, 2163-2177. [CrossRef]

22. Kvamme, B.; Aromada, S.A.; Kuznetsova, T.; Gjerstad, P.B.; Canonge, P.C.; Zarifi, M. Maximum tolerance for water content at various stages of a Natuna production. Heat Mass Transf. 2018, 55, 1059-1079. [CrossRef]

23. Kvamme, B.; Aromada, S.A. Alternative routes to hydrate formation during processing and transport of natural gas with significant amount of CO2: Sleipner gas as a case study. J. Chem. Eng. Data 2018, 63, 832-844. [CrossRef] 
24. Aromada, S.A.; Kvamme, B. Impacts of $\mathrm{CO} 2$ and $\mathrm{H} 2 \mathrm{~S}$ on the risk of hydrate formation during pipeline transport of natural gas. Front. Chem. Sci. Eng. 2019, 13, 616-627. [CrossRef]

25. Aromada, S.A.; Kvamme, B. New approach for evaluating the risk of hydrate formation during transport of hydrocarbon hydrate formers of sI and sII. AIChE J. 2019, 65, 1097-1110. [CrossRef]

26. Kvamme, B. Kinetics of hydrate formation from nucleation theory. Int. J. Offshore Polar 2002, 12, $256-263$.

27. Kvamme, B. Droplets of dry ice and cold liquid CO2 for self-transport of $\mathrm{CO} 2$ to large depths. Int. J. Offshore Polar 2003, 13, 139-146.

28. Kvamme, B.; Selvåg, J.; Aromada, S.K.; Saeidi, N.; Kuznetsova, T. Methanol as hydrate inhibitor and hydrate activator. Phys. Chem. Chem. Phys. 2018, 20, 21968-21987. [CrossRef]

29. Kim, H.; Bishnoi, P.; Heidemann, R.; Rizvi, S. Kinetics of methane hydrate decomposition. Chem. Eng. Sci. 1987, 42, 1645-1653. [CrossRef]

30. Kvamme, B.; Aromada, S.A.; Berge Gjerstad, P. Consistent Enthalpies of the Hydrate Formation and Dissociation Using Residual Thermodynamics. J. Chem. Eng. Data 2019, 64, 3493-3504. [CrossRef]

31. Plimpton, S. Fast Parallel Algorithms for Short-Range Molecular Dynamics. J. Comp. Phys. 1995, 117, 1-19. [CrossRef]

32. Mohammad, N. Heterogeneous Hydrate Nucleation on Calcite $\{1014\}$ and Kaolinite $\{001\}$ Surfaces: A Molecular Dynamics Simulation Study. Master's Thesis, University of Bergen, Bergen, Norway, 2016.

33. Geissbühler, P.; Fenter, P.; DiMasi, E.; Srajer, G.; Sorensen, L.B.; Sturchio, N.C. Three-dimensional structure of the calcite-water interface by surface X-ray scattering. Surf. Sci. 2004, 573, 191-203. [CrossRef]

34. Tatiana, K.; Bjørnar, J.; Bjørn, K.; Sara, S. Water-wetting surfaces as hydrate promoters during transport of carbon dioxide with impurities. Phys. Chem. Chem. Phys. 2015, 17, 12683-12697. [CrossRef]

35. Bjørnar, J. Investigations into the Impact of Solid Surfaces in Aqueous Systems. Ph.D. Thesis, University of Bergen, Bergen, Norway, 2016.

36. Phan Van, C. Transport and Adsorption of CO2 and $\mathrm{H} 2 \mathrm{O}$ on Calcite and Clathrate Hydrate. Ph.D. Thesis, University of Bergen, Bergen, Norway, 2012.

37. Nesse Knarvik, A.B. Examination of Water and Methane Structuring at a Hematite Surface in the Presence of MEG. Master's Thesis, Department of Physics and Technology University of Bergen, Bergen, Norway, 2017.

38. Austrheim, M.H. Evaluation of Methane and Water Structure at a Hematite Surface-A Hydrate Prevention Perspective. Master's Thesis, Department of Physics and Technology, University of Bergen, Bergen, Norway, 2017.

39. Kvamme, B.; Zhao, J.; Wei, N.; Kuznetsova, T.; Sun, W.; Zarifi, M.; Saeidi, N.; Zhou, S.; Li, Q.; Nes Leirvik, K. Effect of mineral surfaces on water structuring, thermodynamics and hydrate nucleation. Energies 2020, In preparation.

40. Schoderbek, D.; Farrell, H.; Hester, K.; Howard, J.; Raterman, K.; Silpngarmlert, S.; LloydMartin, K.; Smith, B.; Klein, P. ConocoPhillips Gas Hydrate Production Test Final Technical Report (1 October 2008-30 June 2013); ConocoPhillips Company for United States Department of Energy National Energy Technology Laboratory: Houston, TX, USA, 2013.

41. Wan, Q.C.; Si, H.; Li, B.; Li, G. Heat transfer analysis of methane hydrate dissociation by depressurization and thermal stimulation. Int. J. Heat Mass Transf. 2018, 127, 206-217. [CrossRef]

42. Available online: https://www.netl.doe.gov/node/7285 (accessed on 4 November 2019).

43. Birkedal, K.A.; Freeman, C.M.; Moridis, G.J.; Graue, A. Numerical Predictions of Experimentally Observed Methane Hydrate Dissociation and Reformation in Sandstone. Energy Fuels 2014, 28, 5573-5586. [CrossRef]

44. Kvamme, B.; Vafaei, M.T.; Chejara, A.; Jemai, K. Simulation of Hydrate Dynamics in Reservoirs. In Proceedings of the 7th International Conference on Gas Hydrates (ICGH 2011), Edinburgh, UK, 17-21 July 2011.

45. Jemai, K.; Vafaei, M.T.; Kvamme, B.; Chejara, A. Simulation of CO2 hydrate formation in cold aquifers: Nonequilibrium approach. Arab. J. Geosci. 2017, 10, 113. [CrossRef]

46. Huang, D.; Fan, S. Measuring and modeling thermal conductivity of gas hydrate-bearing sand. J. Geophys. Res. 2005, 110. [CrossRef]

47. Cho, W.J.; Kwon, S.; Choi, J.W. The thermal conductivity for granite with various water contents. Eng. Geol. 2009, 107, 167-171. [CrossRef]

48. Alishaev, M.G.; Abdulagatov, I.M.; Abdulagatova, Z.Z. Effective thermal conductivity of fluid-saturated rocks experiment and modeling. Eng. Geol. 2012, 135-136, 24-39. [CrossRef] 
49. Midttømme, K.; Roaldset, E.; Aagaard, P. Thermal conductivities of argillaceous sediments. Geol. Soc. 1997, 12, 355-363. [CrossRef]

50. Ramires, M.; Nieto de Castro, C.; Nagasaka, Y.; Nagashima, A.; Assael, M.; Wakeham, W. Standard Reference Data for the Thermal Conductivity of Water. J. Phys. Chem. Ref. Data 1995, 24, 1377-1381. [CrossRef]

51. Sun, S.; Zhao, J.; Zhao, J.; Hao, Y.; Yang, J. The effective thermal conductivity of methane hydrate-bearing seasand. J. Chem. Thermodyn. 2019, 132, 423-431. [CrossRef]

52. Cook, J.G.; Leaist, D.G. An exploratory study of the thermal conductivity of methane hydrate. Geophys. Res. Lett. 1983, 10, 397-399. [CrossRef]

53. Huang, D.; Fan, S. Thermal Conductivity of Methane Hydrate Formed from Sodium Dodecyl Sulfate Solution. J. Chem. Eng. Data 2004, 49, 1479-1482. [CrossRef]

54. Rosenbaum, E.J.; English, N.J.; Johnson, J.K.; Shaw, D.W.; Warzinski, R.P. Thermal Conductivity of Methane Hydrate from Experiment and Molecular Simulation. J. Phys. Chem. B 2007, 111, 13194-13205. [CrossRef] [PubMed]

55. Waite, W.F.; Stern, L.A.; Kirby, S.H.; Winters, W.J.; Mason, D.H. Simultaneous determination of thermal conductivity, thermal diffusivity and specific heat in sI methane hydrate. Geophys. J. Int. 2007, 169, 767-774. [CrossRef]

56. Riedel, M.; Collett, T.S. Observed correlation between the depth to base and top of gas hydrate occurrence from review of global drilling data. Geochem. Geophys. Geosyst. 2017, 18, 2543-2561. [CrossRef]

57. Shankar, U.; Sain, K.; Riedel, M. Assessment of gas hydrate stability zone and geothermal modeling of BSR in the Andaman Sea. J. Asian Earth Sci. 2014, 79, 358-365. [CrossRef]

58. Lee, J.Y.; Kim, G.Y.; Kang, N.K.; Yi, B.Y.; Jung, J.W.; Im, J.H.; Son, B.K.; Bahk, J.J.; Chun, J.H.; Ryu, B.J.; et al. Physical properties of sediments from the Ulleung Basin, East Sea: Results from Second Ulleung Basin Gas Hydrate Drilling Expedition, East Sea (Korea). Mar. Pet. Geol. 2013, 47, 43-55. [CrossRef]

59. Su, M.; Yang, R.; Wang, H.; Sha, Z.; Liang, J.; Wu, N.; Qiao, S.; Cong, X. Gas hydrates distribution in the Shenhu area, northern South China Sea: Comparisons between the eight drilling sites with gas-hydrate petroleum system. Geol. Acta 2016, 14, 79-100.

60. Field, M.E.; Kvenvolden, K.A. Gas hydrates on the northern California continental margin. Geology 1985, 13, 517-520. [CrossRef]

61. Holder, G.D.; Malone, R.D.; Lawson, W.F. Effects of Gas Composition and Geothermal Properties on the Thickness and Depth of Natural-Gas-Hydrate Zones. Soc. Pet. Eng. 1987. [CrossRef]

62. Liu, Y.; Hou, J.; Zhao, H.; Liu, X.; Xia, Z. A method to recover natural gas hydrates with geothermal energy conveyed by CO2. Energy 2018, 144, 265-278. [CrossRef]

63. Bouchafaa, W.; Dalmazzone, D. Thermodynamic equilibrium data for mixed hydrates of $\mathrm{co}_{2}-\mathrm{n}_{2}, \mathrm{CO}_{2}-\mathrm{ch}_{4}$ and $\mathrm{CO}_{2}-\mathrm{h}_{2}$ in pure water and TBAB solutions. In Proceedings of the 7 th International Conference on Gas Hydrates, Edinburgh, UK, 17-21 July 2011.

64. Herri, J.-M.; Bouchemoua, A.; Kwaterski MFezoua, A.; Ouabbas, Y.; Cameirao, A. Gas hydrate equilibria for $\mathrm{CO}_{2}-\mathrm{N}_{2}$ and $\mathrm{CO}_{2}-\mathrm{CH}_{4}$ gas mixtures-Experimental studies and thermodynamic modelling. Fluid $\mathrm{Ph}$. Equilib. 2011, 301, 171-190. [CrossRef]

65. Falenty, A.; Genov, G.; Hansen, T.C.; Kuhs, W.F.; Salamatin, A.N. Kinetics of $\mathrm{CO}_{2}$-hydrate formation from water frost at low temperatures: Experimental results and theoretical model. J. Phys. Chem. C 2010, 115, 4022-4032. [CrossRef]

66. Hovland, M.; Svensen, H. Submarine pingoes: Indicators of shallow gas hydrates in a pockmark at Nyegga, Norwegian Sea. Mar. Geol. 2006, 228, 15-23. [CrossRef]

67. Paull, C. Realizing the Energy Potential of Methane Hydrate for the United States. In Committee on Assessment of the Department of Energy's Methane Hydrate Research and Development Program: Evaluating Methane Hydrate as a Future Energy Resource; The national academies: Washington, DC, USA, 2010; ISBN 0-309-14890-1.

68. Luo, M.; Chen, L.; Wang, S.; Yan, W.; Wang, H.; Chen, D. Pockmark activity inferred from pore water geochemistry in shallow sediments of the pockmark field in southwestern Xisha Uplift, northwestern South China Sea. Mar. Pet. Geol. 2013, 48, 247-259. [CrossRef]

69. Kvamme, B.; Aromada, S.A.; Saeidi, N.; Hustache-Marmou, T.; Berge Gjerstad, P. Hydrate nucleation, growth and induction. ACS Omega, in press. 
70. Qorbani, K. Non-Equilibrium Modelling of Hydrate Phase Transition Kinetics in Sediments. Ph.D. Thesis, University of Bergen, Bergen, Norway, 2017.

71. Aromada, S.A.; Kvamme, B.; Wei, N.; Saeidi, N. Enthalpies of Hydrate Formation and Dissociation from Residual Thermodynamics. Energies 2019, 12, 4726. [CrossRef] 